\title{
O SALÁRIO MÍNIMO COMO INSTRUMENTO DE COMBATE À POBREZA EXTREMA: ESTARIAM ESGOTADOS SEUS EFEITOS?
}

\author{
Luís Eduardo Afonso * \\ Paula Carvalho Pereda ${ }^{\dagger}$ \\ FABIO Giambiagi ${ }^{\ddagger}$ \\ SAMUEL Franco $\S$
}

\begin{abstract}
Resumo
Este artigo analisa a evolução do salário mínimo no Brasil após o Plano Real e os seus efeitos na pobreza extrema. Entre 1994 e 2008, o salário mínimo acumulou um aumento real de quase $110 \%$, crescendo em relação à renda média no país. Atualmente, o salário mínimo chega a $40 \%$ da renda média brasileira. Este artigo atenta para a redução da efetividade de aumentos reais do salário mínimo como instrumento para a redução da pobreza extrema. Sugere-se que o valor real do salário mínimo seja mantido e que os gastos públicos sejam focalizados em políticas sociais mais efetivas.
\end{abstract}

Palavras-chave: Salário Mínimo, Pobreza, Pobreza Extrema

\begin{abstract}
This paper analyses the evolution of the minimum wage in Brazil after the Real Plan and its effects on the extreme poverty. Between 1994 and 2008, the minimum wage had an accumulated real increase of almost $110 \%$, growing in relation to average income in the country. Currently, the minimum wage is about $40 \%$ of national average income. The article points to the reduction of the effectiveness of real increases of minimum wage as a means to reduce the extreme poverty. It is suggested to maintain the real value of the minimum wage and to concentrate the public expenditures in better focused social policies.
\end{abstract}

Keywords: Minimum Wage, Poverty, Extreme Poverty

JEL classification: E24, I32, I38

\footnotetext{
*(FEA-USP) - lafonso@usp.br

† (FEA-USP) - pereda@usp.br

‡ (BNDES) - fgiambia@bndes.gov.br

$\S$ (Consultor do IPEA) - samolivafranco@gmail.com
} 


\section{Introdução}

Em 2007 o Governo propôs uma regra de reajuste para o salário mínimo (SM) válida para o quadriênio 2008/2011. De acordo com essa regra, o aumento real anual do SM tem sido igual ao crescimento defasado do PIB. Após esse período, a nova política de reajustes está em aberto. ${ }^{1}$ Tal política pública poderá ter impactos importantes, tanto no mercado de trabalho, quanto no tocante aos gastos públicos. Dada a relevância do tema, este texto procura fazer uma reflexão acerca dos efeitos dos aumentos do SM sobre a redução da pobreza extrema.

Em que pesem melhorias recentes nos indicadores sociais, dois pontos ainda são preocupantes, para os formuladores de políticas públicas. O primeiro é a má distribuição de renda. O Brasil tem ocupado uma das últimas posições nesse quesito. O segundo ponto são as taxas de pobreza e indigência. Parte importante da população das grandes metrópoles e de alguns bolsões da área rural, particularmente na região nordeste, vive em inquietante miséria. Compreensivelmente, o binômio pobreza-desigualdade tem sido objeto de atenção da sociedade. É natural que as políticas públicas procurem priorizar o combate a essas mazelas. Em função dessa justa motivação, para a opinião pública o ataque à desigualdade e à redução da pobreza tem sido associado a demandas em favor de aumentos reais do SM. Tais aumentos são vistos, tanto pelo cidadão comum como pelo Parlamento (e muitas vezes pelo Executivo), como a forma por excelência de atuação do Estado na superação daqueles dois problemas. Este artigo procura demonstrar que essa suposição, em boa parte, não é adequada. Procura-se argumentar que há certa falta de sintonia entre o que a sabedoria convencional julga que sejam os efeitos dessa política e os resultados efetivos da mesma.

O artigo está dividido em oito seções, incluindo esta breve introdução. Inicialmente faz-se uma sucinta revisão da literatura que trata do tema. A seguir, são expostos os objetivos que os governos idealmente procuram alcançar quando aumentam a variável em questão. Depois, são apresentados dados referentes ao SM após o Plano Real. A quinta e a sexta seções mostram algumas evidências, a partir dos microdados da Pesquisa Nacional por Amostra de Domicílios (PNAD) do IBGE, no período 1996-2007, que indicam que a eficácia do SM como instrumento para atingir tais objetivos foi se diluindo com o passar dos anos, na medida em que a variável teve incrementos reais sucessivos. Destacam-se aqui os valores desagregados por região do país. Com base nos dados apresentados, a sétima seção formula algumas ideias que deveriam nortear políticas sociais alternativas àquelas seguidas até agora, enfatizando a questão da previdência social. Por último, apresentam-se os comentários finais.

\section{Uma breve revisão da literatura}

Nos últimos anos tem havido uma tênue, porém perceptível queda na desigualdade no Brasil (Ferreira et al. 2006). Esse fato tem sido objeto de alguns

\footnotetext{
${ }^{1}$ O Projeto de Lei enviado ao Congresso define a regra para 2008/2011 e estabelece no artigo $4^{\circ}$ que "até 31 de dezembro de 2011, o Poder Executivo da União encaminhará ao Congresso Nacional Projeto de Lei dispondo sobre a política de valorização do salário mínimo para o período compreendido entre 2012 e 2023, inclusive".
} 
estudos. Barros et al. (2006) quantificam a importância dos fatores demográficos, de alterações no mercado de trabalho e dos programas de transferência social. Firpo \& Reis (2006) focam sua preocupação no papel do SM na desigualdade de renda no Brasil, no período 1992-2004. Seu principal achado é que durante o período de inflação mais elevada o SM teve importante papel na redução da desigualdade. A partir da queda dos níveis de inflação, após 1994, essa influência se reduziu. Essa conclusão é corroborada por trabalho posterior (Firpo \& Reis 2007), em que o mesmo tema é revisitado, desta vez, com dados referentes ao período 2001-2005. Parcela importante dessa linha de trabalhos tem sua atenção voltada para a contribuição efetiva de programas oficiais focalizados, como o Programa Bolsa Família (PBF), para essa queda da desigualdade. Um exemplo é Soares (2006b). Uma abordagem semelhante é feita por Barros (2007). Empregando uma metodologia de simulações contrafactuais, com base em dados da PNAD 2005, o autor avalia que o PBF é bem mais efetivo que o SM no combate à pobreza e na redução da desigualdade ${ }^{2}$.

Uma segunda linha de trabalhos trata da possível relação entre a evolução do salário mínimo e os níveis de pobreza no país. Barros et al. (2000), com uma análise de equilíbrio geral, encontraram relação positiva entre aumentos no SM e redução na pobreza, quando são levados em conta os efeitos sobre os benefícios previdenciários. Um ponto importante é verificar qual a fração das despesas advindas de uma elevação do SM é efetivamente destinada às famílias extremamente pobres. Barros \& Carvalho (2005), empregando dados da PNAD 2003, mostraram a reduzida eficácia do SM como instrumento para o ataque à pobreza extrema. A partir do conceito de insuficiência de renda (representado pela diferença entre a renda que define a linha de pobreza extrema e a renda das famílias extremamente pobres) os autores mostraram que, dada uma despesa adicional de $\mathrm{R} \$ 3,1$ bilhões, associada a um aumento de $10 \%$ do piso previdenciário, apenas cerca de $\mathrm{R} \$ 0,1$ bilhão era destinado efetivamente às famílias extremamente pobres.

Mais recentemente, o tema voltou a ser abordado por Saboia (2007a), que chega a uma conclusão similar, reconhecendo a pouca eficácia do SM como política adequada para a redução da pobreza absoluta ${ }^{3}$. Nas palavras do autor "...é preciso reconhecer, por fim, que o fato de, diretamente, o SM atingir pouco as famílias mais pobres significa que sua capacidade para a redução da pobreza absoluta é limitada...". Na mesma linha, Neri et al. (2006) concluem que "talvez estejamos próximos do valor máximo do mínimo em termos de impactos favoráveis na pobreza sob a ótica trabalhista. Neste sentido, o salário mínimo não deveria figurar no elenco de políticas promotoras do crescimento". Note-se, no entanto, que nos dois trabalhos citados neste parágrafo o foco dos autores está na simulação de eventuais impactos de mudanças no SM sobre indicadores de desigualdade e não sobre a redução da extrema pobreza ${ }^{4}$ como é o caso deste artigo.

Com base nos trabalhos listados, parece ser razoável afirmar que há espaço para reflexões adicionais sobre a relação entre salário mínimo e redução da pobreza extrema. Com ênfase complementar à literatura listada, na seção seguinte os dados são apresentados desagregados por região, fato importante

\footnotetext{
${ }^{2}$ Essa conclusão confirma os resultados obtidos por Barros et al. (2006).

${ }^{3}$ Os argumentos do autor são também apresentados em (Saboia 2006) e (Saboia 2007b).

${ }^{4}$ Uma parte dos resultados de Neri et al. (2006) é feita com base em dados da PME, o que restringe sua análise à meia dúzia de metrópoles em que esta pesquisa é realizada.
} 
em um país como o Brasil em que as desigualdades regionais são expressivas. Faz-se também um esforço adicional de análise e quantificação dos efeitos de aumentos do SM sobre a previdência social, ponto este que não é destacado em nenhuma das contribuições acima referenciadas na revisão da literatura nacional. E também na seção final, com base nos resultados apresentados, são feitas algumas recomendações de políticas públicas. Essa pretende ser a contribuição deste artigo.

\section{Objetivos da política de aumentos reais do salário mínimo}

É possível afirmar que a política de aumentos do valor real do SM tem dois objetivos fundamentais. O primeiro seria atacar o problema representado pela pobreza extrema. O aumento da variável serviria para promover uma alta das remunerações inferiores, aproximando-as do que corresponderia ao valor de subsistência de uma família. Para que esse raciocínio seja válido (e essa política pública eficaz), é necessário que o valor do SM seja inferior àquele que corresponderia a uma linha de "pobreza extrema" para uma família. Desta maneira, aumentos do SM aproximariam seu valor daquele considerado minimamente desejável.

O segundo objetivo seria a diminuição do grau de desigualdade na distribuição de renda. Portanto, os aumentos do SM inserem-se no conjunto de políticas de cunho redistributivo, pautadas pela busca de maior equidade. Dentre tais políticas pode-se destacar a política fiscal. Na parte tributária, pode haver tributos com alíquotas progressivas (como por exemplo, o imposto de renda pessoa física). Do lado dos dispêndios, podem ser empregadas as transferências diretas de renda às famílias mais pobres, cujo programa mais emblemático no Brasil é o Bolsa Família. É consensual admitir que a redução da desigualdade é um valor absoluto muito importante no Brasil. Com base nesse entendimento, aqueles que propugnam em favor de aumentos do valor real do SM veem nessa política uma forma de elevar a base das remunerações, diminuindo a relação entre os ganhos das camadas mais ricas e mais pobres na população brasileira.

A importância fiscal da variável resulta do artigo 201 da Constituição de 1988, que estabelece que "nenhum benefício que substitua o salário de contribuição ou o rendimento do trabalho do segurado terá valor mensal inferior ao salário mínimo". Este é complementado pelo artigo 203 que estabelece "a garantia de um salário mínimo de benefício mensal à pessoa portadora de deficiência e ao idoso que comprovem não possuir meios de prover a própria manutenção ou de tê-la provida por sua família". Ambos os artigos citados deixaram de ser mecanismos de proteção do poder aquisitivo dos benefícios inferiores e se tornaram na prática um instrumento de efetiva elevação do valor real do piso. É necessário ressaltar que desde o início da vigência do SM em 1940, este esteve associado à expressão do direito a uma renda mínima, que permitiria satisfazer as necessidades básicas do trabalhador e de sua família. Em 1988, tal concepção foi cristalizada no artigo 7 da Constituição, que no capítulo dos direitos sociais do trabalhador estabelece o "salário mínimo, fixado em lei, nacionalmente unificado, capaz de atender a suas necessidades vitais básicas e às de sua família [...] com reajustes periódicos que lhe preservem o poder aquisitivo". Embora na Constituição conste apenas a expressão "preservar o poder aquisitivo", parece ser razoável inferir que a elevação real 
do SM ao longo do tempo pode ter sido pautada pelo reconhecimento de que o valor inicialmente estabelecido para a variável não atendia aos requisitos do artigo 7. Com base nesse diagnóstico, as políticas públicas deveriam ter como objetivo aproximar a variável de um valor que efetivamente atendesse àquele conjunto de necessidades.

Há três canais de propagação da política de aumentos no SM. O primeiro é de natureza compulsória, uma vez que no mercado formal o empregador é obrigado a seguir parâmetros determinados legalmente. O segundo é o caráter de indexador da variável. O SM funciona como piso para outras fontes de rendimentos, que não aquelas recebidas no mercado de trabalho. Esse é o caso do seguro-desemprego e do piso previdenciário e assistencial. O terceiro canal refere-se ao "efeito farol", termo criado por Souza \& Baltar (1982), apud Neri et al. (2001). Este efeito consiste no poder de balizamento que o SM legalmente determinado tem sobre o mercado informal, que a priori estaria fora de sua abrangência ${ }^{5}$. Embora, pela própria definição de informalidade, nada impeça que o mínimo imposto pela legislação seja ignorado, considerações de caráter ético ou de conveniência prática podem levar os empregadores a seguir os parâmetros da legislação, ainda que informalmente.

\section{O salário mínimo depois do Plano Real}

Desde a deflagração do Plano Real, o SM tem sofrido aumentos reais sucessivos praticamente todos os anos. Tendo como base a situação em dezembro de 1994 e adotando o IPCA como deflator, os aumentos reais foram da ordem de 29,5\% no primeiro governo Cardoso (1995/1998), 10,0\% no segundo $(1999 / 2002)$ e de $46,6 \%$ nos 6 primeiros anos completos $(2003 / 2008)$ do governo Lula, totalizando um crescimento acumulado de 108,3\% em 14 anos. Estes dados podem ser vistos na Tabela 1.

Essa substantiva elevação contrasta com a trajetória do rendimento médio real do trabalho das pessoas com idade igual ou superior a 10 anos, conforme pode ser visto na Tabela $2^{6}$. Há um claro descompasso entre o rendimento médio do mercado de trabalho, formado pela interação entre oferta e demanda de trabalho, e o valor do SM, determinado pelo governo.

Tamanha elevação do SM em um contexto de reduzido dinamismo econômico foi uma das causas da elevação dos dispêndios previdenciários. Os gastos do INSS com benefícios em 1995, primeiro ano completo pós-estabilização, eram de 4,6\% do PIB e devem ultrapassar 7,3\% em 2009 do PIB. O efeitopreço do SM foi intensificado pela expansão na quantidade de benefícios assistenciais, cujo piso, por força da lei, é $1 \mathrm{SM}$. As despesas com benefícios tipo LOAS/RMV, inexistentes na conta do Tesouro em 1994 e que em 1998 eram de apenas $0,1 \%$ do PIB, chegaram a 0,2\% do PIB em 2002 e em 2009 serão de aproximadamente $0,6 \%$ do PIB. Paralelamente, as despesas do FAT ligadas ao abono salarial e ao seguro-desemprego passaram de 0,5\% do PIB em 1995, para cerca de $0,8 \%$ do PIB em 2009.7

\footnotetext{
${ }^{5}$ Para uma análise anterior sobre a eficácia do salário mínimo, ver Velloso (1990)

${ }^{6} \mathrm{Na}$ Tabela 1, adota-se o IPCA como deflator, por ser a medida oficial de inflação. Já na Tabela 2 os valores são calculados pelo IBGE, empregando o INPC. A diferença acumulada entre o IPCA e o INPC é ínfima: entre junho de 1994 e dezembro de 2008 o primeiro teve um aumento acumulado de cerca de $237 \%$ e o segundo de $246 \%$. Em termos reais, isso implica uma diferença de $3 \%$, irrelevante face às dimensões da variação do salário mínimo no período.

${ }^{7}$ No caso do gasto de LOAS/RMV, parte do crescimento se deve ao fato de que benefícios de
} 
Tabela 1: Salário mínimo (Valores em dezembro)

\begin{tabular}{lcrrrc}
\hline Ano & $\begin{array}{c}\text { Valor } \\
\text { (R\$ correntes })\end{array}$ & $\begin{array}{c}\text { Variação SM } \\
(\%)\end{array}$ & $\begin{array}{c}\text { IPCA } \\
(\%)\end{array}$ & $\begin{array}{r}\text { Variação real SM } \\
(\%)\end{array}$ & $\begin{array}{c}\text { Índice real } \\
(\text { dez./94 }\end{array}$ \\
\hline 1994 & 70 & & & & $100)$ \\
1995 & 100 & 42,86 & 22,4 & 16,7 & 116,7 \\
1996 & 112 & 12,00 & 9,6 & 2,2 & 119,3 \\
1997 & 120 & 7,14 & 5,2 & 1,8 & 121,5 \\
1998 & 130 & 8,33 & 1,7 & 6,6 & 129,5 \\
1999 & 136 & 4,62 & 8,9 & $-4,0$ & 124,3 \\
2000 & 151 & 11,03 & 6,0 & 4,8 & 130,2 \\
2001 & 180 & 19,21 & 7,7 & 10,7 & 144,2 \\
2002 & 200 & 11,11 & 12,5 & $-1,3$ & 142,4 \\
2003 & 240 & 20,00 & 9,3 & 9,8 & 156,3 \\
2004 & 260 & 8,33 & 7,6 & 0,7 & 157,4 \\
2005 & 300 & 15,38 & 5,7 & 9,2 & 171,8 \\
2006 & 350 & 16,67 & 3,1 & 13,1 & 194,4 \\
2007 & 380 & 8,57 & 4,5 & 3,9 & 202,0 \\
2008 & 415 & 9,21 & 5,9 & 3,1 & 208,3 \\
\hline
\end{tabular}

Fonte: Cálculos dos autores com base em dados do IBGE

Tabela 2: Salário mínimo (Valores em dezembro)

\begin{tabular}{lr}
\hline Ano & Índice real \\
\hline 1995 & 100,0 \\
1996 & 101,7 \\
1997 & 100,8 \\
1998 & 101,1 \\
1999 & 94,7 \\
2001 & 93,0 \\
2002 & 90,1 \\
2003 & 82,6 \\
2004 & 82,7 \\
2005 & 87,1 \\
2006 & 92,5 \\
2007 & 94,9 \\
2008 & 98,1 \\
\hline Fonte: Pesquisa Mensal de \\
Emprego (PME) (2007)
\end{tabular}


No caso do INSS, a elevação das despesas como proporção do PIB pode ser explicada por três fatores. Em primeiro lugar, as reduzidas taxas de crescimento do PIB, que se refletiram na trajetória da renda média, apresentada na Tabela 2. Esse fator afeta o denominador da relação Gasto/PIB. Em segundo lugar, a legislação permitiu um crescimento expressivo do número de benefícios. Essa prodigalidade pode ser constatada no grande número de aposentadorias precoces (particularmente por tempo de contribuição), em regras pouco rígidas para a concessão de auxílio-doença e nos bônus aos professores e professoras no cômputo do fator previdenciário. E, em terceiro, o crescimento real do SM, que afeta 2 de cada 3 benefícios. Nos 14 anos de 1994 a 2008 o PIB real cresceu a uma taxa anual média de 3,1\%. No mesmo período, segundo dados do Anuário Estatístico da Previdência Social o número de benefícios estritamente previdenciários em manutenção (sem contar os acidentários e assistenciais) aumentou a uma média anual de 3,3\%, ou seja, 58\% em termos acumulados. Já o gasto real do INSS (empregando o deflator implícito do PIB), nesses mesmos 14 anos expandiu-se a uma média anual de 5,7\%, o que representou um acumulado de $117 \%$ no período. Este valor é bastante superior ao incremento físico de benefícios, devendo-se essa diferença ao aumento do valor médio dos benefícios, resultante da elevação real do SM e, por conseguinte, do piso previdenciário.

\section{Houve redução na eficácia da política de aumentos do salário mínimo como mecanismo de combate à pobreza extrema?}

Conforme mencionado anteriormente, é fundamental verificar a fração das despesas advindas de uma elevação do SM que é destinada efetivamente às famílias extremamente pobres. Dois casos polares ajudam a compreender melhor esse ponto. No primeiro caso, seja um arranjo familiar composto por apenas uma única pessoa, recebedora de um LOAS no valor de $\mathrm{R} \$ 465$. Suponhase que a linha de pobreza extrema seja de $\mathrm{R} \$ 130$ per capita. Se houver um aumento no valor do SM, este incremento de renda não reduz a pobreza extrema. A insuficiência de renda das famílias extremamente pobres não se altera, visto que antes do aumento essa pessoa já se encontrava acima da linha da pobreza extrema. No segundo caso, um beneficiário do LOAS tem três dependentes menores de idade. A renda per capita dessa família é de $\mathrm{R} \$ 116,25$. Se o SM aumentar para, por exemplo, $\mathrm{R} \$ 520$, todo o adicional per capita de renda de $\mathrm{R} \$ 13,75$ destina-se a diminuir a cobrir a insuficiência de renda dessa família. Portanto, o incremento no SM atende ao objetivo proposto. De forma genérica, pode-se postular que a eficácia da política de aumento do piso previdenciário e assistencial para diminuir a insuficiência de renda será uma função direta: ${ }^{8}$

- da proporção de famílias extremamente pobres em que algum dos membros recebe uma remuneração nas proximidades de um SM;

- da proporção de famílias extremamente pobres que tem um idoso entre seus membros.

RMV cessados por falecimento foram sendo substituídos por concessões do tipo LOAS. A distorção se deve ao fato de que as RMV não eram computadas nas contas do Tesouro Nacional (sem INSS) até 2003, quando passaram a ser especificadas como uma das rubricas do gasto desagregado do Tesouro. De qualquer forma, entre 1994 e 2008, o total de benefícios assistenciais (RMV mais LOAS) passou de 1,4 milhão para 3,3 milhões.

${ }^{8}$ Sobre estas questões, ver os artigos clássicos de Ramos \& Reis (1993) e Ramos \& Reis (1995). 
Com base na argumentação até aqui desenvolvida, apresentam-se a seguir as Tabelas 3 a 10. Os dados fornecem o embasamento para que se possa inferir que a política de aumentos do SM como mecanismo de combate à pobreza extrema vem perdendo eficácia ao longo do tempo, de forma quase que proporcional ao aumento de seu valor real. Em 2007 quase 32\% das pessoas com rendimento positivo ganhava no máximo $1 \mathrm{SM}$. Note-se que esta parcela variou ao longo do tempo, oscilando entre $23,4 \%$ (1996) e 35,7\% (2006). Há ainda diferenças regionais, sendo essa parcela mais expressiva nas regiões norte e nordeste, justamente as mais pobres do país. Essa informação é desagregada nas Tabelas 3 e 4 . Na primeira estão representados os indivíduos com rendimento inferior a $1 \mathrm{SM}$ e na segunda, os que apresentam um rendimento exatamente igual a $1 \mathrm{SM}$. Em ambas as tabelas os dados referem-se à renda do trabalho principal das pessoas com rendimento positivo e idade igual ou superior a 10 anos. As proporções são referentes ao total de trabalhadores.

Tabela 3: Percentual de trabalhadores com renda inferior a $1 \mathrm{SM}$

\begin{tabular}{ccccccr}
\hline Ano & Brasil & Norte & Nordeste & Centro-Oeste & Sudeste & Sul \\
\hline 1995 & 14,8 & 13,3 & 34,0 & 10,5 & 7,1 & 9,5 \\
1996 & 15,0 & 14,2 & 34,9 & 9,9 & 7,1 & 10,3 \\
1997 & 15,3 & 15,4 & 35,1 & 10,2 & 7,4 & 9,5 \\
1998 & 16,4 & 18,8 & 36,5 & 10,4 & 7,9 & 11,2 \\
1999 & 17,5 & 19,2 & 38,2 & 12,8 & 8,7 & 11,7 \\
2001 & 19,3 & 19,1 & 40,0 & 14,0 & 11,1 & 13,2 \\
2002 & 19,3 & 20,2 & 40,2 & 13,9 & 11,1 & 12,6 \\
2003 & 21,7 & 24,0 & 43,3 & 14,8 & 13,4 & 14,4 \\
2004 & 21,8 & 23,0 & 43,4 & 15,3 & 13,8 & 14,3 \\
2005 & 20,9 & 21,0 & 42,3 & 13,9 & 13,1 & 13,5 \\
2006 & 22,4 & 24,6 & 43,6 & 16,1 & 14,4 & 15,4 \\
2007 & 20,8 & 23,0 & 41,5 & 15,0 & 12,9 & 14,3 \\
\hline
\end{tabular}

Fonte: PNADs 1995-2007. Tabulações dos autores.

Tabela 4: Percentual de trabalhadores com renda igual a 1 SM

\begin{tabular}{rrrccrr}
\hline Ano & Brasil & Norte & Nordeste & Centro-Oeste & Sudeste & Sul \\
\hline 1995 & 12,2 & 14,2 & 15,9 & 14,8 & 10,4 & 9,8 \\
1996 & 8,4 & 10,9 & 10,7 & 11,6 & 7,1 & 6,5 \\
1997 & 10,3 & 13,9 & 14,6 & 12,3 & 8,0 & 8,1 \\
1998 & 8,8 & 12,0 & 12,1 & 11,3 & 6,9 & 6,8 \\
1999 & 6,9 & 8,3 & 9,3 & 8,9 & 5,6 & 5,5 \\
2001 & 9,0 & 11,5 & 13,0 & 10,7 & 7,2 & 6,2 \\
2002 & 12,5 & 18,3 & 17,7 & 14,3 & 9,9 & 9,1 \\
2003 & 10,8 & 14,8 & 16,3 & 12,1 & 8,5 & 7,1 \\
2004 & 10,3 & 13,4 & 15,8 & 10,3 & 8,1 & 7,0 \\
2005 & 14,6 & 19,1 & 20,2 & 16,2 & 12,4 & 10,2 \\
2006 & 13,3 & 16,8 & 18,6 & 14,6 & 11,4 & 8,8 \\
2007 & 11,0 & 14,4 & 17,4 & 12,3 & 8,6 & 6,5 \\
\hline
\end{tabular}

Fonte: PNADs 1995-2007. Tabulações dos autores.

Nossos resultados trazem informações complementares àquelas apresentadas nos trabalhos de Neri et al. (2001) e Firpo \& Reis (2006). No primeiro ar- 
tigo os autores concentram sua atenção nas diferenças entre as categorias ocupacionais. Já no segundo artigo, os resultados são apresentados de forma agregada, para todos os trabalhadores. Além disso, a ênfase do trabalho de Firpo e Reis está na relação entre salário mínimo e desigualdade. Nossa análise apresenta o diferencial de apresentar os dados desagregados regionalmente, abrindo campo às comparações entre as regiões do Brasil, fato importante em um país em que as desigualdades regionais são expressivas. Adicionalmente, cabe mencionar que a contribuição de Neri et al. (2001) enfatiza principalmente os aspectos referentes ao "efeito-farol". Como esses autores utilizaram a PNAD 1996, obviamente seu trabalho não capta os importantes efeitos dos aumentos reais do SM ocorridos de 1994 a 2007. Como nosso trabalho emprega dados das PNADs do período 1995-2007, a contribuição aqui apresentada permite que nossos resultados tenham um caráter temporal mais recente e abrangente.

Uma primeira conclusão emerge das tabelas. Parece haver sensível heterogeneidade da eficácia do SM como instrumento de combate à pobreza extrema nas diversas regiões do país. Se um percentual muito elevado de indivíduos recebe menos de um SM, é perceptível que a eficácia prática da definição de um maior valor legal para o SM pode não ser expressiva. Note-se que na região nordeste (em que há forte concentração de indivíduos extremamente pobres) $42 \%$ dos trabalhadores recebiam em 2007 valores inferiores a um SM, não sendo, a priori, afetados pelo incremento deste. Entretanto, cabe a ressalva de que pode haver trabalhadores cujos rendimentos apesar de inferiores ao salário mínimo, tenham algum tipo de atrelamento ao seu valor. Desta forma, pode-se esperar algum tipo de efeito farol, ainda que em magnitude inferior à da taxa de crescimento do $\mathrm{SM}^{9}$.

A segunda conclusão é o aumento na proporção de indivíduos com renda inferior a um SM. Este fato pode ser compreendido pela observação das Tabelas 2 (que apresenta a virtual estagnação do rendimento médio) e 3. Um caso paradigmático é o de um trabalhador, que ganha inicialmente um SM e que não tenha recebido os aumentos integrais do mínimo ao longo do tempo. Como se pode notar pela observação conjunta das Tabelas 3 e 4, em 1995, 27\% dos trabalhadores tinham rendimento igual ou inferior a um SM. Em 2007, esse valor havia subido para $32 \%$.

Há também evidências de um "efeito arredondamento". Nos anos em que o SM assume um valor arredondado, a proporção de indivíduos que ganha exatamente um SM aumenta. Isso pode ser constatado para os anos de 1995, quando o SM passou a ser de R\$ 100, 2002 (R\$ 200) e 2005 (R\$ 300). O percentual de pessoas que ganhava exatamente um SM revelou-se maior nesses anos, devido aos indivíduos que ganham valores independentes do SM, mas que, circunstancialmente, passam a ter um rendimento idêntico ao deste.

A Tabela 5 mostra uma informação complementar: a proporção de pessoas que recebe múltiplos exatos do SM. Embora a indexação a múltiplos de SM seja proibida, nada impede que informalmente essa vinculação seja feita. Por exemplo, uma empregada doméstica pode receber de sua patroa um salário acertado em termos nominais, mas que corresponde a dois SM. A Tabela 5 mostra com maior intensidade (uma vez que abarca quem recebe diferentes múltiplos do SM) o mesmo fenômeno explicado acima, associado ao efeito do arredondamento do SM nos anos de 1995, 2002 e 2005.

\footnotetext{
${ }^{9}$ Os autores agradecem a um parecerista anônimo pela sugestão sobre esta característica.
} 
Tabela 5: Percentual de trabalhadores com renda igual a 2 ou mais múltiplos exatos de salário mínimo

\begin{tabular}{rrrccrr}
\hline Ano & Brasil & Norte & Nordeste & Centro-Oeste & Sudeste & Sul \\
\hline 1995 & 16,2 & 16,7 & 10,7 & 18,2 & 18,3 & 17,7 \\
1996 & 3,5 & 4,3 & 2,1 & 6,8 & 3,5 & 3,7 \\
1997 & 5,9 & 6,4 & 4,5 & 8,4 & 6,2 & 6,4 \\
1998 & 4,0 & 4,1 & 2,9 & 6,1 & 4,0 & 4,6 \\
1999 & 1,5 & 1,5 & 1,0 & 2,8 & 1,4 & 1,7 \\
2001 & 2,7 & 3,3 & 2,0 & 3,9 & 2,8 & 2,8 \\
2002 & 12,5 & 11,2 & 7,4 & 13,3 & 14,8 & 13,9 \\
2003 & 2,2 & 2,7 & 1,6 & 3,2 & 2,3 & 2,3 \\
2004 & 1,7 & 1,8 & 1,3 & 2,5 & 1,7 & 1,8 \\
2005 & 9,5 & 8,9 & 5,1 & 10,8 & 11,3 & 10,7 \\
2006 & 4,9 & 4,7 & 2,9 & 5,6 & 5,6 & 5,8 \\
2007 & 0,9 & 1,0 & 0,7 & 1,4 & 0,8 & 0,9 \\
\hline
\end{tabular}

Fonte: PNADs 1995-2007. Tabulações dos autores.

A Tabela 6 complementa as informações das Tabela 3 e Tabela 4. Agora os dados são apresentados para as famílias (e não para os indivíduos, como feito anteriormente), por regiões e por categoria de renda. Cerca de $24 \%$ das famílias do Brasil apresentam rendimento mensal familiar per capita igual ou inferior à metade de $1 \mathrm{SM}$. No caso das regiões norte e nordeste, os percentuais são ainda mais elevados, alcançando, respectivamente, $35 \%$ e $43 \%$. Nesses casos, a eficácia da política de aumentos do SM é maior em situações em que essas famílias pobres possuem pelo menos um indivíduo com rendimento em torno de um SM e que possa ser afetado por uma elevação da variável. Se nenhum componente dessas famílias extremamente pobres tiver uma remuneração de $1 \mathrm{SM}$, é de se esperar que o aumento produza poucos resultados para essas famílias. No entanto, dado que o SM tem um efeito balizador sobre outras remunerações, ainda assim pode haver algum efeito positivo.

Tabela 6: Proporção de famílias por classe de rendimento mensal familiar per capita $Y$, por região $(\%)$

\begin{tabular}{lrrccrr}
\hline Faixa de rendimento & Brasil & Norte & Nordeste & Centro-Oeste & Sudeste & \multicolumn{1}{c}{ Sul } \\
\hline$Y<=0,25 \mathrm{SM}$ & 7,9 & 11,6 & 18,5 & 4,3 & 3,4 & 3,2 \\
$0,25 \mathrm{SM}<Y<=0,5 \mathrm{SM}$ & 15,6 & 23,4 & 24,6 & 15,2 & 11,0 & 10,3 \\
$0,5 \mathrm{SM}<Y<=1 \mathrm{SM}$ & 27,0 & 29,0 & 28,4 & 29,3 & 25,9 & 26,0 \\
Demais & 49,5 & 36,0 & 28,5 & 51,2 & 59,7 & 60,5 \\
Total & 100,0 & 100,0 & 100,0 & 100,0 & 100,0 & 100,0 \\
\hline
\end{tabular}

Fonte: PNAD 2007. Síntese de indicadores.

Os dados apresentados logo acima podem ser desagregados. A Tabela 7 apresenta, para os domicílios cuja renda familiar per capita seja igual ou inferior a $1 \mathrm{SM}$, os dados referentes ao número de pessoas que recebem algum rendimento. Conforme pode ser notado, a distribuição das regiões centrooeste, sudeste e sul é bastante similar, com forte concentração de uma ou duas pessoas com rendimento no domicílio. Para as demais regiões (norte e nordeste) há uma proporção ligeiramente maior de domicílios onde há três ou mais pessoas com rendimentos. 
Tabela 7: Distribuição de famílias residentes em domicílios particulares com renda familiar per capita até $1 \mathrm{SM}$, por grandes regiões, segundo a distribuição do rendimento intrafamiliar (\%)

\begin{tabular}{lrrrrrr}
\hline $\begin{array}{l}\text { Número de pessoas que } \\
\text { recebem } \begin{array}{c}\text { algum } \\
\text { mento na família }\end{array}\end{array}$ & Brasil & Norte & Nordeste & Centro-Oeste & Sudeste & Sul \\
\hline Zero & 2 & 2 & 1 & 2 & 3 & 2 \\
Uma & 39 & 38 & 33 & 44 & 43 & 43 \\
Duas & 41 & 39 & 45 & 39 & 38 & 41 \\
Três & 12 & 14 & 13 & 11 & 11 & 11 \\
Quatro & 4 & 5 & 5 & 3 & 3 & 2 \\
Cinco ou mais & 2 & 2 & 2 & 1 & 1 & 1 \\
\hline
\end{tabular}

PNAD 2007. Síntese dos indicadores.

A Tabela 8 apresenta a proporção dos domicílios em que o total dos rendimentos é inferior ao mínimo de subsistência. Com base nos dados, dois pontos devem ser ressaltados. O primeiro são as claras diferenças regionais, que não haviam sido destacadas pelos demais autores antes citados que abordaram o tema. O segundo ponto é a relativa estabilidade da proporção até o ano 2001. No ano seguinte, devido ao aumento da inflação, que atingiu o patamar dos dois dígitos, e a variação real negativa no valor do SM (ver Tabela 1), a proporção cresce em todas as regiões do país, com maior destaque para o norte e o nordeste. Em 2003 há uma reversão à média do período anterior a 2002. A partir de 2005 parece haver uma mudança na estabilidade apontada anteriormente, com queda na proporção de domicílios abaixo do mínimo de subsistência. Ressalte-se que mesmo em um ano de forte aumento real do SM, como 2001, não se notou uma queda pronunciada da variável em questão. Este fato parece ser uma evidência contrária à existência de efeitos mais intensos do SM sobre a pobreza extrema.

Mesmo em termos regionais, em 2003 a proporção de domicílios com rendimentos inferiores ao mínimo de subsistência era praticamente a mesma que no início do período. A exceção é a região sul, onde ocorrera uma queda importante, de 2 pontos percentuais. Ou seja, apesar do aumento real acumulado de 34\% entre 1995 e 2003 (Tabela 1), neste período praticamente não houve mudanças na proporção de domicílios em situação de extrema pobreza, o que é mais uma evidência de que o SM pode não ser o melhor instrumento para atacar o problema da pobreza extrema. A redução do percentual de domicílios muito pobres depois de 2003, captada pela Tabela 8, parece se dever, em boa parte, à incidência do Programa Bolsa Família, de caráter mais focalizado que os aumentos reais do SM.

Deve ser ressaltado que a escolha da linha de pobreza ou da renda mínima de subsistência não é única. Diferentes metodologias de cálculo podem levar a linhas distintas e, portanto, a uma classificação de um contingente diferente de indivíduos como pobres ou como parte da pobreza extrema. Esta discussão é feita por alguns autores. Podem ser citados os trabalhos de Groedhart et al. (1977), que discute o próprio conceito da linha de pobreza e as maneiras de mensurar esta variável e Hagenaars \& Van Praag (1985), que apresenta, por exemplo, uma definição particular de linha de pobreza. Mais recentemente, Ravallion et al. (2008) apresentam um resumo deste ponto da literatura, ao fazer a comparação dos indicadores de uma extensa série de países. 
Tabela 8: Percentual dos domicílios com soma dos rendimentos inferiores ao mínimo de subsistência (\%)

\begin{tabular}{|c|c|c|c|c|c|c|}
\hline Ano & Brasil & Norte & Nordeste & Centro-Oeste & Sudeste & Sul \\
\hline 1995 & 12,8 & 17,4 & 28,1 & 8,0 & 6,0 & 8,5 \\
\hline 1996 & 13,3 & 18,2 & 30,1 & 8,6 & 5,9 & 8,3 \\
\hline 1997 & 13,5 & 19,1 & 30,1 & 7,2 & 6,2 & 8,3 \\
\hline 1998 & 12,4 & 19,1 & 27,2 & 6,5 & 5,9 & 8,0 \\
\hline 1999 & 13,0 & 19,0 & 28,1 & 7,8 & 6,2 & 8,4 \\
\hline 2001 & 13,0 & 16,5 & 27,8 & 7,4 & 7,0 & 7,3 \\
\hline 2002 & 16,4 & 24,6 & 34,7 & 9,6 & 8,8 & 9,2 \\
\hline 2003 & 12,9 & 17,9 & 27,9 & 7,8 & 7,0 & 6,5 \\
\hline 2004 & 11,0 & 13,6 & 25,0 & 5,2 & 5,6 & 5,5 \\
\hline 2005 & 9,6 & 12,0 & 22,0 & 5,1 & 4,5 & 5,1 \\
\hline 2006 & 7,9 & 10,1 & 18,4 & 4,1 & 3,6 & 4,0 \\
\hline 2007 & 7,8 & 10,1 & 17,6 & 3,8 & 3,9 & 3,6 \\
\hline \multicolumn{7}{|c|}{$\begin{array}{l}\text { Fontes PNAD-IBGE. Tabulações dos autores. Linhas de pobreza com base } \\
\text { no apêndice de Barros et al. (2004) } \\
{ }^{*} \text { As linhas de pobreza são calculadas com base em metade do } \\
\text { salário mínimo vigente a cada ano. A linha de pobreza é calculada } \\
\text { com base em um quarto do salário mínimo. }\end{array}$} \\
\hline
\end{tabular}

A Tabela 9 expõe o aumento relativo da importância do SM ao longo do tempo. Como a variável aumentou em termos reais, ao mesmo tempo em que a renda média da população declinou, a relação entre o SM e as demais rendas da economia sofreu claro incremento. Por exemplo, em 1995 o SM representava $23 \%$ da renda média nacional e em 2007 chegara a $40 \%$ da renda média do país. Em 2007, o SM era $112 \%$ superior à renda média dos $20 \%$ mais pobres e $20 \%$ superior à renda média (RM) dos $50 \%$ mais pobres do país, além de atingir $65 \%$ da RM dos $90 \%$ mais pobres.

De forma análoga ao que foi feito anteriormente, a Tabela 10 apresenta as informações da Tabela 9, mas com a desagregação pelas regiões do país. Para o ano de 2007, observa-se que o SM correspondia a $64 \%$ da renda média da região nordeste e era $77 \%$ superior à renda média dos $50 \%$ mais pobres da região. Deve ainda ser ressaltado que no nordeste, o SM era 5\% maior que a renda média dos $90 \%$ mais pobres.

Analisando os dados por região, há evidências de que houve uma perda de relevância do SM como determinante da situação dos indivíduos mais pobres. Os aumentos reais do SM fizeram com que este se deslocasse de posição na escala de distribuição de renda do trabalho principal. Para o Brasil como um todo, em 1996 o SM se situava no $21^{\circ}$ percentil da distribuição individual de renda; em 2007 o SM se deslocara para o percentil de número 27. Como se pode notar na Tabela 11, esta distorção é ainda mais acentuada no nordeste, região em que o SM encontrava-se em 2007 no $51^{\circ}$ percentil da distribuição. Esta é uma evidência de que o termo "mínimo" parece não ser tão adequado ao SM. 
Tabela 9: PSalário mínimo/Outros indicadores de renda e desigualdade

\begin{tabular}{ccccc}
\hline Ano & SM/RM & $\begin{array}{c}\text { SM/RM } \\
\text { 20\%+pobres }\end{array}$ & $\begin{array}{c}\text { SM/RM } \\
50 \%+\text { pobres }\end{array}$ & $\begin{array}{c}\text { SM/RM } \\
90 \%+\text { pobres }\end{array}$ \\
\hline 1995 & 0,23 & 1,37 & 0,88 & 0,40 \\
1996 & 0,22 & 1,33 & 0,86 & 0,39 \\
1997 & 0,23 & 1,37 & 0,88 & 0,40 \\
1998 & 0,24 & 1,38 & 0,90 & 0,42 \\
1999 & 0,26 & 1,41 & 0,92 & 0,43 \\
2001 & 0,30 & 1,68 & 1,04 & 0,51 \\
2002 & 0,31 & 1,85 & 1,09 & 0,53 \\
2003 & 0,35 & 2,25 & 1,18 & 0,59 \\
2004 & 0,36 & 2,19 & 1,17 & 0,59 \\
2005 & 0,37 & 2,14 & 1,19 & 0,62 \\
2006 & 0,40 & 2,38 & 1,24 & 0,65 \\
2007 & 0,40 & 2,12 & 1,20 & 0,65 \\
\hline
\end{tabular}

Fonte: PNADs 1995-2007. Tabulações dos autores.

Tabela 10: Salário mínimo/Outros indicadores de renda e desigualdade (2007)

\begin{tabular}{lcccc}
\hline \multicolumn{1}{c}{ Região } & SM/RM & $\begin{array}{c}\text { SM/RM } \\
20 \%+\text { pobres }\end{array}$ & $\begin{array}{c}\text { SM/RM } \\
50 \%+\text { pobres }\end{array}$ & $\begin{array}{c}\text { SM/RM } \\
90 \%+\text { pobres }\end{array}$ \\
\hline Brasil & 0,40 & 2,12 & 1,20 & 0,65 \\
Norte & 0,51 & 2,64 & 1,35 & 0,79 \\
Nordeste & 0,64 & 4,52 & 1,77 & 1,05 \\
Centro-Oeste & 0,34 & 1,58 & 1,08 & 0,58 \\
Sudeste & 0,35 & 1,41 & 0,97 & 0,54 \\
Sul & 0,36 & 1,45 & 0,97 & 0,54 \\
\hline
\end{tabular}

PNAD (2007). Tabulações dos autores.

Tabela 11: Localização do SM na distribuição de renda (em décimos da distribuição), em ordem ascendente de rendimento do trabalho principal dos empregados com rendimento

\begin{tabular}{ccccccc}
\hline Ano & Brasil & Norte & Nordeste & Centro-Oeste & Sudeste & Sul \\
\hline 1995 & 21 & 21 & 42 & 18 & 13 & 15 \\
1996 & 20 & 20 & 41 & 16 & 11 & 14 \\
1997 & 21 & 23 & 43 & 17 & 12 & 14 \\
1998 & 21 & 25 & 43 & 17 & 12 & 15 \\
1999 & 21 & 24 & 43 & 18 & 12 & 15 \\
2001 & 24 & 25 & 47 & 20 & 15 & 17 \\
2002 & 26 & 30 & 50 & 22 & 17 & 18 \\
2003 & 28 & 32 & 52 & 21 & 18 & 18 \\
2004 & 27 & 30 & 52 & 21 & 18 & 18 \\
2005 & 29 & 31 & 53 & 23 & 20 & 19 \\
2006 & 30 & 34 & 53 & 24 & 21 & 20 \\
2007 & 27 & 31 & 51 & 22 & 18 & 18 \\
\hline
\end{tabular}

Fonte: PNADs 1995-2007. Tabulações dos autores. 


\section{Um olhar adicional sobre a pobreza e a pobreza extrema no Brasil}

Na seção anterior foram apresentados dados referentes à eficiência do salário mínimo como mecanismo de combate à pobreza no país. Um olhar adicional, mais detalhado, sobre a questão a pobreza (e a pobreza extrema) no país pode ser feito por meio do conjunto de índices FGT, que foram propostos no artigo clássico de Foster et al. (1984). Usando a notação de Hoffman (1998), estes índices podem ser escritos pela 1 .

$$
\varphi(\alpha)=\frac{1}{n z^{\alpha}} \sum_{i=1}^{p}\left(z-x_{i}\right)^{\alpha},
$$

Quando $\alpha=0$, o índice é igual à proporção de pobres (ou de indivíduos extremamente pobres, conforme sua construção. As Tabelas 12 e 13 a seguir apresentam estes indicadores. Conforme pode ser notado, a proporção de pobres na população apresenta grande estabilidade até 2002. Em 2003 notase um ligeiro aumento neste indicador para todas as regiões, com exceção da região da sudeste. A partir de 2004, há uma mudança notável. Ocorre uma expressiva redução na pobreza, na maior parte dos casos superior a 10 pontos percentuais, em todas as regiões do país. O mesmo padrão pode ser verificado para a pobreza extrema (Tabela 8). Neste caso destaca-se a região nordeste, onde a redução foi superior a 13 pontos percentuais. Também deve ser ressaltado, que, embora uma clara diminuição nos índices de pobreza e pobreza extrema tenha sido verificada, as desigualdades regionais continuam evidentes. Este fato pode ser constatado por meio da comparação das regiões sul, sudeste e centro-oeste com a região nordeste.

Tabela 12: Porcentagem de pessoas pobres

\begin{tabular}{ccccccc}
\hline Ano & Brasil & Norte & Nordeste & Centro-Oeste & Sudeste & Sul \\
\hline 1995 & 38,6 & 49,1 & 65,7 & 23,9 & 30,2 & 30,2 \\
1996 & 38,2 & 50,6 & 65,8 & 23,0 & 29,3 & 30,7 \\
1997 & 38,7 & 51,4 & 66,2 & 23,7 & 30,4 & 28,2 \\
1998 & 37,4 & 50,8 & 64,0 & 23,1 & 28,4 & 27,2 \\
1999 & 39,0 & 52,7 & 65,0 & 24,8 & 30,4 & 29,6 \\
2001 & 38,7 & 50,2 & 64,2 & 25,6 & 27,7 & 28,7 \\
2002 & 38,3 & 51,5 & 63,7 & 25,5 & 26,2 & 27,8 \\
2003 & 39,4 & 53,7 & 64,7 & 26,8 & 26,1 & 29,3 \\
2004 & 37,0 & 48,4 & 62,6 & 24,9 & 23,3 & 24,9 \\
2005 & 34,2 & 45,4 & 58,9 & 22,0 & 22,3 & 23,2 \\
2006 & 29,7 & 41,1 & 52,9 & 18,1 & 18,8 & 18,4 \\
2007 & 28,1 & 39,4 & 50,5 & 17,1 & 16,3 & 17,1 \\
\hline
\end{tabular}

Fonte: PNADs 1995-2007. Tabulações dos autores.

Quando $\alpha=1$, o índice é igual ao hiato de pobreza. Este é uma medida de intensidade da pobreza, dada pela ponderação da proporção de pobres pela insuficiência de renda. Os dados relativos à pobreza e à pobreza extrema são mostrados nas Tabelas 14 e 15, respectivamente. Pode-se verificar que o padrão de redução verificado para este indicador é bastante similar àquele verificado para a proporção de pobres. 
Tabela 13: Porcentagem de pessoas extremamente pobres

\begin{tabular}{rcccccr}
\hline Ano & Brasil & Norte & Nordeste & Centro-Oeste & Sudeste & Sul \\
\hline 1995 & 17,3 & 22,1 & 35,7 & 7,9 & 11,1 & 9,8 \\
1996 & 17,7 & 23,1 & 37,7 & 7,5 & 10,8 & 10,2 \\
1997 & 17,8 & 23,7 & 38,0 & 7,8 & 10,6 & 9,0 \\
1998 & 16,8 & 24,1 & 34,9 & 7,5 & 10,7 & 8,1 \\
1999 & 17,4 & 23,8 & 35,6 & 8,1 & 11,2 & 9,5 \\
2001 & 17,4 & 21,5 & 35,3 & 9,0 & 9,8 & 9,4 \\
2002 & 16,5 & 22,0 & 33,6 & 8,3 & 8,6 & 8,8 \\
2003 & 17,5 & 23,1 & 35,4 & 9,0 & 8,8 & 10,0 \\
2004 & 15,1 & 18,0 & 32,0 & 7,3 & 7,5 & 6,7 \\
2005 & 13,3 & 16,0 & 28,3 & 6,1 & 6,8 & 6,4 \\
2006 & 10,8 & 13,2 & 23,7 & 4,7 & 5,4 & 4,8 \\
2007 & 10,3 & 13,0 & 22,2 & 4,6 & 4,6 & 4,3 \\
\hline
\end{tabular}

Fonte: PNADs 1995-2007. Tabulações dos autores.

Tabela 14: Hiato de pobreza (\%)

\begin{tabular}{ccccccc}
\hline Ano & Brasil & Norte & Nordeste & Centro-Oeste & Sudeste & Sul \\
\hline 1995 & 17,8 & 22,4 & 33,9 & 9,4 & 12,4 & 12,2 \\
1996 & 18,1 & 23,5 & 35,2 & 9,4 & 12,1 & 12,6 \\
1997 & 18,1 & 24,3 & 35,1 & 9,3 & 12,4 & 11,1 \\
1998 & 17,3 & 24,3 & 32,9 & 9,2 & 11,9 & 10,4 \\
1999 & 18,0 & 24,2 & 33,5 & 9,7 & 12,9 & 11,6 \\
2001 & 18,0 & 23,0 & 33,3 & 10,5 & 11,4 & 11,5 \\
2002 & 17,2 & 23,3 & 32,2 & 9,9 & 10,2 & 10,9 \\
2003 & 18,2 & 24,2 & 33,6 & 10,8 & 10,3 & 11,7 \\
2004 & 16,2 & 20,4 & 30,9 & 9,4 & 9,1 & 9,0 \\
2005 & 14,7 & 18,5 & 28,3 & 8,1 & 8,4 & 8,7 \\
2006 & 12,4 & 15,8 & 24,7 & 6,5 & 6,8 & 6,6 \\
2007 & 11,9 & 16,1 & 23,5 & 6,2 & 6,2 & 6,2 \\
\hline
\end{tabular}

Fonte: PNADs 1995-2007. Tabulações dos autores.

Tabela 15: Hiato de extrema pobreza (\%)

\begin{tabular}{ccccccc}
\hline Ano & Brasil & Norte & Nordeste & Centro-Oeste & Sudeste & Sul \\
\hline 1995 & 7,1 & 8,4 & 15,0 & 3,3 & 4,3 & 4,2 \\
1996 & 7,7 & 9,4 & 16,7 & 3,3 & 4,5 & 4,7 \\
1997 & 7,5 & 9,4 & 16,3 & 3,4 & 4,1 & 3,9 \\
1998 & 7,0 & 9,7 & 14,4 & 3,2 & 4,3 & 3,5 \\
1999 & 7,2 & 9,5 & 14,7 & 3,3 & 4,7 & 3,8 \\
2001 & 7,4 & 8,6 & 15,0 & 4,0 & 4,0 & 4,2 \\
2002 & 6,6 & 8,3 & 13,6 & 3,3 & 3,1 & 3,9 \\
2003 & 7,3 & 8,8 & 14,9 & 3,8 & 3,4 & 4,1 \\
2004 & 6,1 & 6,6 & 12,9 & 3,0 & 2,9 & 2,8 \\
2005 & 5,3 & 5,5 & 11,3 & 2,5 & 2,6 & 2,9 \\
2006 & 4,4 & 4,4 & 9,5 & 2,1 & 2,1 & 2,1 \\
2007 & 4,5 & 5,4 & 9,5 & 2,2 & 2,0 & 2,2 \\
\hline
\end{tabular}

Fonte: PNADs 1995-2007. Tabulações dos autores. 
Finalmente, quando $\alpha=2$ é válida, o índice pode ser interpretado como a severidade da pobreza (ou da pobreza extrema). Os dados são apresentados nas Tabelas 16 e 17, respectivamente. Novamente nota-se relativa estabilidade no indicador até 2002, aumento em 2003 e posterior redução expressiva a partir de 2004. Também se repete o claro contraste entre as regiões sul, sudeste e centro-oeste frente à região nordeste.

Tabela 16: Severidade da pobreza (\%)

\begin{tabular}{rrrcccc}
\hline Ano & Brasil & Norte & Nordeste & Centro-Oeste & Sudeste & Sul \\
\hline 1995 & 10,9 & 13,4 & 21,6 & 5,4 & 7,1 & 7,0 \\
1996 & 11,4 & 14,4 & 23,1 & 5,4 & 7,1 & 7,4 \\
1997 & 11,2 & 14,7 & 22,9 & 5,4 & 7,0 & 6,4 \\
1998 & 10,6 & 15,0 & 20,9 & 5,3 & 7,0 & 5,9 \\
1999 & 10,9 & 14,7 & 21,3 & 5,5 & 7,6 & 6,5 \\
2001 & 11,1 & 13,7 & 21,4 & 6,2 & 6,6 & 6,7 \\
2002 & 10,3 & 13,7 & 20,2 & 5,6 & 5,6 & 6,3 \\
2003 & 11,1 & 14,3 & 21,5 & 6,2 & 5,8 & 6,8 \\
2004 & 9,6 & 11,5 & 19,2 & 5,2 & 5,0 & 4,9 \\
2005 & 8,5 & 10,1 & 17,3 & 4,4 & 4,6 & 4,9 \\
2006 & 7,2 & 8,5 & 14,9 & 3,6 & 3,7 & 3,6 \\
2007 & 7,1 & 9,2 & 14,4 & 3,5 & 3,4 & 3,6 \\
\hline
\end{tabular}

Fonte: PNADs 1995-2007. Tabulações dos autores.

Tabela 17: Severidade da pobreza extrema (\%)

\begin{tabular}{ccccccc}
\hline Ano & Brasil & Norte & Nordeste & Centro-Oeste & Sudeste & Sul \\
\hline 1995 & 4,3 & 4,8 & 8,7 & 2,2 & 2,6 & 2,7 \\
1996 & 4,9 & 5,7 & 10,2 & 2,3 & 2,7 & 3,4 \\
1997 & 4,6 & 5,4 & 9,7 & 2,3 & 2,6 & 2,7 \\
1998 & 4,2 & 5,8 & 8,1 & 2,2 & 2,7 & 2,4 \\
1999 & 4,3 & 5,7 & 8,3 & 2,2 & 2,9 & 2,5 \\
2001 & 4,7 & 5,0 & 8,9 & 2,8 & 2,5 & 2,9 \\
2002 & 3,9 & 4,6 & 7,8 & 2,2 & 1,8 & 2,7 \\
2003 & 4,4 & 5,0 & 8,7 & 2,5 & 2,1 & 2,8 \\
2004 & 3,6 & 3,7 & 7,4 & 2,0 & 1,7 & 1,9 \\
2005 & 3,1 & 2,9 & 6,5 & 1,6 & 1,6 & 2,0 \\
2006 & 2,6 & 2,4 & 5,4 & 1,4 & 1,3 & 1,4 \\
2007 & 3,0 & 3,6 & 5,9 & 1,6 & 1,4 & 1,8 \\
\hline
\end{tabular}

Fonte: PNADs 1995-2007. Tabulações dos autores.

\section{Evidências empíricas dos efeitos da política de aumentos do salário mínimo como mecanismo de combate à pobreza}

Os dados apresentados nas seções anteriores forneceram algumas evidências sobre a evolução do SM e da pobreza (e pobreza extrema) utilizando microdados das PNADs. No período analisado o SM teve expressivo aumento real, de forma quase monotônica (a exceção são os anos 1999 e 2002). Já a proporção de pessoas em condição de extrema pobreza mostra, em termos gerais estabilidade até 2003, reduzindo-se a partir deste ano. Até esta etapa do estudo não 
se pode rejeitar a possibilidade de variações no SM terem impactos nos níveis de pobreza. Por este motivo procura-se nesta seção analisar se a efetividade da política de aumentos reais do SM aumentou ou reduziu ao longo dos anos.

Para tanto, pretende-se verificar se o SM teve papel na redução da pobreza e da pobreza extrema no país. Um dos indicadores para medir a pobreza (extrema) de uma população é o percentual de indivíduos cujos rendimentos são inferiores aos rendimentos considerados na linha de pobreza (extrema). Sendo assim, uma vez que se disponha da evolução de tais linhas de pobreza ao longo do tempo, pode-se quantificar os impactos do SM, controlando-se por fatores exógenos que influenciam na redução/aumento da pobreza no país.

De forma a medir o comportamento acima descrito, esta seção pretende fornecer os insumos para responder à seguinte questão:

de que maneira mudanças no valor do salário mínimo, para os indivíduos cujos salários são indexados ao $\mathrm{SM}$, afetam a probabilidade de as famílias estarem acima das linhas de pobreza e de pobreza extrema? Ou seja, qual a sensibilidade da pobreza, e pobreza extrema, a variações no SM?

Em outras palavras, pretende-se verificar o sinal da diferença entre as duas probabilidades dadas pela 2. Esse procedimento visa mensurar eventuais mudanças na probabilidade de indivíduos com um determinado conjunto de características observáveis $X$ no período $t$ estarem abaixo da linha da pobreza, com relação à indivíduos com o mesmo conjunto de características observáveis, no período $t-1^{10}$. Na 2, Y it é a renda do indivíduo $i$ no período $t, L P t$ é a linha de pobreza no períodot e $S M t$ é a variável que indica se o indivíduo tem uma renda de um salário mínimo no período $t$

$$
P\left(Y_{i t}<L P_{t} \mid S M_{t}, X_{t}\right)-P\left(Y_{i t-1}<L P_{t-1} \mid S M_{t-1}, X_{t}\right),
$$

Em termos práticos, essas probabilidades podem ser medidas pela transformação do evento considerado $\left(Y_{i t}<L P_{t}\right)$ em uma variável dicotômica, ou seja, cria-se uma variável que assume o valor 1 , para o caso de a renda estar abaixo da linha de pobreza em cada período $t$ em questão.

A modelagem do evento por uma variável dicotômica possibilita o tratamento econométrico por meio de modelos de probabilidade. O princípio básico destes modelos é o fato de a variável dependente $Y$ assumir apenas dois valores: 1 para o caso de interesse e 0 em caso contrário. Nesse tipo de modelagem, visa-se encontrar o efeito de uma mudança em uma variável explicativa $X$ sobre a probabilidade condicional $Y / X$. No caso específico deste estudo, supõe-se que dentro da matriz de controles $X$ esteja, também, a variável que mede a vinculação do indivíduo ao salário mínimo definido pelo governo federal. Para quantificar tais efeitos, empregou-se um modelo Logit, que pode ser descrito da seguinte maneira:

$$
P(Y=1 \mid X)=G(X \beta)
$$

\footnotetext{
${ }^{10}$ Esta diferenciação é importante, visto que a base de dados formada pelas PNADs não é um painel com os mesmos indivíduos, mas sim vários conjuntos de observações de diferentes indivíduos em diferentes momentos do tempo.
} 
A função $G($.) descreve a distribuição acumulada logística e sua utilização está associada à hipótese de os erros do modelo seguirem tal distribuição ${ }^{11}$, assim:

$$
G(X \beta)=\Lambda(X \beta)=\frac{\exp (X \beta)}{1+\exp (X \beta)},
$$

É importante ressaltar que neste tipo de modelo o vetor de parâmetros $\beta$ associados às variáveis explicativas não tem a interpretação usual dos modelos de regressão tradicionais, ou seja, estes parâmetros não representam diretamente os efeitos marginais das variáveis explicativas sobre a variável dependente. Para se obter estes efeitos, devem ser encontrados os efeitos marginais do modelo, por meio da 5 :

$$
\frac{\partial E[Y \mid X]}{\partial X}=\Lambda(X \beta)[1-\Lambda(X \beta)] \beta
$$

Esta expressão mostra que os efeitos marginais dependem das informações referentes ao vetor de variáveis explicativas $X$. Por essa razão, para a interpretação do modelo estimado, é útil calcular os efeitos marginais avaliados nas médias dos regressores, ou seja, os efeitos marginais para domicílios com características médias Greene (2003).

De forma consistente com as estatísticas apresentadas nas seções anteriores, as bases de dados utilizadas para as estimações foram as PNADs de 1996 a $2007^{12}$. A unidade de análise são os domicílios pesquisados em cada ano da PNAD. Os dados foram empilhados de maneira a testar os efeitos de mudanças no salário mínimo e de outras variáveis, ao longo do tempo. A justificativa para o empilhamento dos dados está baseada em duas razões principais: a primeira é que, conforme apresentado na 2, pretende-se verificar a diferença nas probabilidades causada pela mudança no SM (sob a hipótese de todos os demais controles estarem constantes, $X t$ ) de o indivíduo estar abaixo da linha de pobreza. Para isso é necessária a estimação de, pelo menos dois anos em conjunto, de maneira a permitir a comparabilidade dos resultados. A segunda razão é que a estimação conjunta permite que seja testada a igualdade entre os coeficientes de cada ano, além de resultar em coeficientes mais robustos.

No caso em estudo neste trabalho, a variável dependente $Y$ assume valor 1 se os moradores do domicílio têm renda per capita inferior à linha de pobreza (extrema) e 0 em caso contrário. O conjunto de variáveis $X$ reflete os fatores exógenos que afetam a probabilidade de o domicílio estar abaixo da linha de pobreza. Fazem parte de $X$ variáveis sócioeconômicas dos chefes dos domicílios e dos demais membros da família, assim como informações sobre as condições de inserção destes indivíduos no mercado de trabalho. No caso de a análise envolver diversos períodos e regiões, é importante adicionar à matriz $X$ variáveis que captem a temporalidade da amostra, assim como as diferenças regionais existentes dentro do país (efeitos específicos regionais e de tempo). Em resumo, as seguintes variáveis compõem a matriz $X$ : escolaridade, estado civil, idade, ocupação e raça do chefe da família; escolaridade média dos indivíduos ocupados da família; SM; tamanho do domicílio; variáveis dummy

\footnotetext{
${ }^{11}$ Ver Wooldridge (2002).

${ }^{12}$ Devido ao volume grande de informações, foi retirada uma amostra aleatória de $50 \%$ de cada ano das informações originais da PNAD, restando 543.950 observações.
} 
de anos e de localização dos domicílios; variáveis dummy para a situação de formalidade/informalidade no trabalho do chefe do domicílio; entre outras.

Para medir especificamente o efeito do salário mínimo na probabilidade de os domicílios estarem abaixo da linha de pobreza, foram construídas variáveis que representam a vinculação dos trabalhadores ao salário mínimo, ou seja, identifica os trabalhadores cujos rendimentos estejam indexados ao valor do mínimo federal (e também aos seus múltiplos). Assim, foram construídas variáveis dummies que identificavam, dentro dos domicílios, esses trabalhadores, separando-os no caso de indivíduos ocupados, aposentados e pensionistas.

Em outras palavras, para se medir a dependência dos trabalhadores com relação ao SM, empregou-se o seguinte procedimento: se o valor do rendimento do trabalho de algum morador do domicílio está indexado em múltiplos do SM (até o teto de $6 \mathrm{SM}$ ), a variável assume valor unitário para este domicílio, caso contrário a variável terá valor nulo. O mesmo procedimento foi realizado para os rendimentos não provenientes do trabalho, tais como aposentadorias e pensões. Foram também criadas as variáveis cruzadas, com as interações entre as dummies da dependência do SM e os anos considerados na análise, com a intenção de captar possíveis efeitos temporais que afetem as pessoas que recebem rendimentos indexados ao SM. Vale ressaltar que, apesar de serem considerados os rendimentos dos trabalhadores indexados a múltiplos do SM até $6 \mathrm{SM}$, os indivíduos com rendimentos de 1 ou 2 SM representam $96,8 \%$, em média, desses casos. Como o máximo de moradores do domicílio é 20 , e o número de membros do domicílio é controlado pelo modelo, considerou-se o máximo de 6 vezes o SM como o maior valor indexado ao piso que poderia causar impacto no percentual de pobres (ou pobres extremos) $)^{13}$. Os casos em que o rendimento era 6 vezes o valor do SM representaram, em média, apenas $0,13 \%$ de todos os rendimentos indexados ao piso federal considerados. A Tabela A.1 no anexo traz a descrição das variáveis utilizadas e suas principais estatísticas descritivas amostrais.

Tendo em vista os objetivos do trabalho, foram estimadas duas regressões para mensurar a importância do SM na probabilidade de os domicílios estarem abaixo das linhas de pobreza (designada por $L P 2$ ) e de pobreza extrema $(L P 1)$. O valor de $L P 1$ corresponde à metade de $L P 2$. A primeira regressão tem seus resultados apresentados, de forma resumida na Tabela $18^{14}$. Os valores dos coeficientes são os efeitos marginais das variáveis calculados nas médias das variáveis ${ }^{15}$. Vale enfatizar que a especificação apresentada representa a especificação final estimada ${ }^{16}$.

Os coeficientes estimados representam o impacto de cada variável na probabilidade de pobreza extrema, i.e. a probabilidade marginal da pobreza extrema. Sendo assim, coeficientes negativos representam redução na pobreza e coeficientes positivos representam incremento na pobreza. Para verificar estes efeitos ao longo dos anos considerados na amostra, pode-se comparar os coe-

\footnotetext{
${ }^{13}$ Em outras palavras, acredita-se que indivíduos que recebam múltiplos maiores de 6 SM já excluiriam automaticamente sua família da linha de pobreza.

${ }^{14}$ Devido aos limites de espaço, os resultados completos não são apresentados. Estes podem ser disponibilizados mediante solicitação aos autores.

${ }^{15}$ No caso das dummies, foram consideradas as médias como as proporções de resposta positiva na amostra, de maneira que o perfil médio considerado seja a proporção da característica na amostra.

${ }^{16}$ As outras formas funcionais estimadas não apresentaram resultados substancialmente distintos. Estes exercícios podem ser obtidos mediante solicitação aos autores.
} 
Tabela 18: Efeitos marginais das variáveis de controle na média amostral - Linha de pobreza extremat

\begin{tabular}{|c|c|c|c|}
\hline \multicolumn{4}{|c|}{ Regressão Logística } \\
\hline \multicolumn{4}{|c|}{$\begin{array}{l}\text { Variável Dependente: } \mathrm{P}(\text { abaixo de LP1 }) \\
\text { Estatística Wald chi2 }=68.655,26-\mathrm{p} \text {-valor }=0 \\
\text { Pseudo } \mathrm{R}^{2}=0.4134\end{array}$} \\
\hline Variável & Efeito Marginal & Variável & Efeito Marginal \\
\hline idade & $-0,00182^{*}$ & renda_sm & $-0,04572^{*}$ \\
\hline casado & 0,00157 & renda_sm96 & $0,11861^{*}$ \\
\hline num_filhos & $0,01813^{*}$ & renda_sm97 & $0,07705^{*}$ \\
\hline num_parentes & 0,00003 & renda_sm98 & $0,09495^{*}$ \\
\hline num_empregados & $-0,01813^{*}$ & renda_sm99 & $0,09625^{*}$ \\
\hline branco & $-0,01890$ & renda_sm01 & $0,06153^{*}$ \\
\hline negro & $-0,00545$ & renda_sm02 & $0,04535^{*}$ \\
\hline amarelo & $-0,01023$ & renda_sm03 & $0,05588^{*}$ \\
\hline pardo & $-0,00983$ & renda_sm04 & $0,04341^{*}$ \\
\hline indigena & $-0,00678$ & renda_sm05 & $0,01791^{*}$ \\
\hline le_e_escreve & $-0,00330^{*}$ & renda_sm06 & $-0,00051$ \\
\hline trabalho_semana & $-0,04444^{*}$ & renda_apos_sm & $-0,03540^{*}$ \\
\hline auxilio_moradia & $-0,01800^{*}$ & renda_apos_sm96 & $0,03662^{*}$ \\
\hline auxilio_alim & $-0,01845^{*}$ & renda_apos_sm97 & $0,04300^{*}$ \\
\hline auxilio_trans & $-0,02436^{*}$ & renda_apos_sm98 & $0,02427^{*}$ \\
\hline auxilio_educ & $-0,01042^{*}$ & renda_apos_sm99 & $0,02110^{*}$ \\
\hline auxilio_saud & $-0,02357^{*}$ & renda_apos_sm01 & 0,01127 \\
\hline escol_media & $-0,00707^{*}$ & renda_apos_sm02 & $0,01417^{*}$ \\
\hline EMPR & $-0,03398^{*}$ & renda_apos_sm03 & 0,00291 \\
\hline CONT & $-0,02189^{*}$ & renda_apos_sm04 & 0,00794 \\
\hline SREM & $0,02811^{*}$ & renda_apos_sm05 & 0,00711 \\
\hline CCAR & $-0,02849^{*}$ & renda_apos_sm06 & $-0,00001$ \\
\hline SCAR & $-0,01614^{*}$ & renda_pens_sm & $-0,03349^{*}$ \\
\hline FPUB & $-0,02571^{*}$ & renda_pens_sm96 & $0,03788^{*}$ \\
\hline MILI & $-0,02878^{*}$ & renda_pens_sm97 & $0,03795^{*}$ \\
\hline 1996 & $-0,00745^{*}$ & renda_pens_sm98 & $0,03614^{*}$ \\
\hline 1997 & $-0,00149$ & renda_pens_sm99 & $0,04943^{*}$ \\
\hline 1998 & $-0,00488^{*}$ & renda_pens_sm01 & 0,01624 \\
\hline 1999 & $-0,00123$ & renda_pens_sm02 & $0,02720^{*}$ \\
\hline 2001 & $0,00522^{*}$ & renda_pens_sm03 & 0,01310 \\
\hline 2002 & $0,03974^{*}$ & renda_pens_sm04 & 0,01039 \\
\hline 2003 & $0,01257^{*}$ & renda_pens_sm05 & 0,00397 \\
\hline 2004 & $0,00618^{*}$ & renda_pens_sm06 & $-0,01375^{*}$ \\
\hline 2005 & $0,00846^{*}$ & Num_moradores & $-0,00064$ \\
\hline 2006 & 0,00116 & & \\
\hline
\end{tabular}

significativo a 1\%. Fonte: cálculos dos autores.

${ }^{+}$Em ambas as estimações, cujos resultados são apresentados nas Tabelas 18 e 19, foram suprimidas as dummies referentes ao ano de 2007, de maneira a facilitar a comparação dos resultados. 
ficientes das iterações das variáveis com as dummies de cada ano, criadas de forma que a dummy base está referenciada ao ano de 2007. Desta forma, os coeficientes estimados para renda_sm,renda_apos_sm e renda_pens_sm referemse ao efeito marginal para 2007, cujo sinal é negativo e significativo para as três variáveis consideradas. Ou seja, ter o rendimento vinculado ao SM em 2007 reduziu a probabilidade de as famílias estarem abaixo da linha de pobreza extrema. Para os efeitos dos demais anos, deve-se combinar o efeito de 2007 com o efeito da variável iterada do ano em questão ${ }^{17}$.

Desta forma, o efeito do SM ao longo do tempo na probabilidade de entrada/saída da pobreza é captado pela diferença anual entre os coeficientes das variáveis renda_sm, renda_apos_sm e renda_pens_sm, que possuem interações com os anos da amostra. Grande parte dos coeficientes estimados para essas variáveis foi estatisticamente significante a $5 \%$, o que indica que o valor referencial do SM (tanto na indexação do rendimento do trabalho, quanto do piso de aposentadorias e pensões) contribuiu, em média para, combater a pobreza extrema do período. Este comportamento foi observado porque os coeficientes estimados para renda_sm,renda_apos_sm e renda_pens_sm foram decrescentes ao longo dos anos, implicando a diminuição média da proporção de indivíduos extremamente pobres ${ }^{18}$. Os anos de 2006 e 2007 foram os que apresentaram coeficientes mais negativos para estes impactos, nas três dimensões consideradas (trabalho, aposentadorias e pensões).

Entretanto, a variação anual dos efeitos estimados da indexação ao SM na probabilidade de pobreza extrema não parece acompanhar exatamente o ganho real do SM no período de 1996 a 2006. Como exemplo, tem-se o ano de 1998, no qual o valor real do SM teve aumento superior a 6,5\% (ver Tabela 1). Neste ano, o efeito médio do SM na redução da pobreza extrema foi igual ao efeito do ano de 1999, em que o SM real teve uma variação negativa de cerca de 4\%. Resultados similares também são verificados em 2001 e 2003 . Embora nestes anos tenham ocorridos expressivos aumentos reais no SM $(10,7 \%$ e 9,8\%, respectivamente), os efeitos da indexação dos rendimentos ao SM na probabilidade de os domicílios pertencerem à linha de pobreza extrema foram semelhante aos efeitos dos anos de 2002 e 2004, cujos reajustes reais do piso federal foram de $-1,26 \%$ e $0,68 \%$, respectivamente. Em suma, os resultados indicaram uma influência positiva no combate à pobreza extrema por parte da indexação de rendimentos ao SM, porém (e este é um ponto fundamental) este estímulo parece ter se desvinculado dos aumentos reais do salário mínimo nos últimos 10 anos da amostra.

As variáveis binárias que medem os efeitos temporais - dummies de tempo que mensuram os efeitos específicos dos anos da amostra - apontam para um comportamento estável da medição da pobreza extrema ao longo do tempo. Ou seja, os resultados dos coeficientes das variáveis temporais indicam pouca variabilidade - inferior a $1 \%$ - na proporção de domicílios extremamente pobres no período analisado. Exceção é feita ao ano de 2002, que apresenta maior massa de domicílios abaixo da linha de pobreza extrema. Tal situação,

\footnotetext{
${ }^{17}$ Para o ano de 2006, por exemplo, a variável renda_sm06 não foi estatisticamente significante a $5 \%$, o que significa dizer que o efeito da indexação ao SM sobre a pobreza foi estatisticamente igual ao efeito estimado para 2007. Sendo assim, a probabilidade marginal estimada para esta variável no ano de 2006 foi a mesma probabilidade estimada para o ano de 2007 (dummy base).

${ }^{18}$ Realizou-se, também, um teste conjunto destas variáveis para verificar se os efeitos da indexação foram constantes ao longo do tempo. O teste de igualdade rejeita fortemente [Estatística $\left.\chi^{2}(11)=1.159,71\right]$ a hipótese de efeitos iguais entre os anos.
} 
já evidenciada na Tabela 8, parece ser reflexo de um conjunto peculiar de condições político-econômicas então prevalecentes. A perspectiva de mudanças na condução da política econômica, dadas as perspectivas referentes à eleição presidencial de 2002 levou a uma desvalorização da taxa de câmbio real. Este fato resultou em aumento nos preços dos bens importados, com elevação nos índices de inflação, não acompanhada pelos reajustes salariais, o que levou à redução no poder aquisitivo dos trabalhadores assalariados ${ }^{19,20}$.

A seguir, foi estimado um segundo modelo, no qual a variável dependente é a probabilidade de os domicílios estarem abaixo das linhas de pobreza regional. Os resultados resumidos são apresentados na Tabela 19.

A interpretação dos sinais dos coeficientes estimados da Tabela 19 segue a mesma lógica do modelo estimado para a probabilidade de pobreza extrema, apresentado na Tabela 18.

Novamente, os coeficientes estimados para renda_sm, renda_apos_sm e renda_pens_sm referem-se ao efeito marginal para 2007, cujos sinais também mostraram efeito negativo e significante para as três variáveis consideradas. Estes resultados sugerem que a vinculação do rendimento ao SM no ano de 2007 reduziu a probabilidade de as famílias com esta condição estarem abaixo da linha de pobreza.

Como os efeitos marginais foram decrescentes ao longo dos anos (e estatisticamente significantes a $5 \%$ ), há evidências que o SM possui um efeito médio negativo na probabilidade de pobreza, tanto na indexação do rendimento do trabalho, quanto de aposentadorias e pensões. Deve ser destacado que o coeficiente do efeito do SM sobre aposentadorias e pensões foi em média bastante negativo, principalmente a partir de 2001, resultados estes mais expressivos, no que se refere ao combate à pobreza, do que os encontrados no modelo de pobreza extrema. Entretanto, novamente repete-se o padrão dos resultados da regressão apresentada na Tabela 18 , da qual se pode inferir que a variação destes efeitos médios ao longo dos anos não parece acompanhar o ganho real do SM no período 21 .

Em resumo, a estimação dos dois modelos apresentados nas Tabelas 18 e 19 sugere a existência de efeito médio negativo ao longo de 1996 a 2007 para

\footnotetext{
${ }^{19}$ Vale ressaltar que a variável que capta o efeito específico médio dos anos também incorpora o resultado das políticas de distribuição de renda levadas à cabo a partir de 2001 , inicialmente o Bolsa Escola e, na sequência, o Bolsa Família.

${ }^{20}$ Os resultados do modelo para estimar os efeitos do salário mínimo sobre a probabilidade de os indivíduos estarem abaixo da linha de pobreza extrema mostram que as variáveis que medem a escolaridade média das pessoas ocupadas na família (variável escol_média), alfabetização (variável le_e_escreve) e idade do chefe da família (variável idade) apresentaram efeito negativo estatisticamente significante, na probabilidade de as famílias estarem abaixo da linha de pobreza extrema. Ou seja, quanto mais escolarizados forem os membros do domicílio, em média, e/ou quanto mais velho for o chefe da família, maiores são as chances de a família não pertencer à classe de pobres extremos. Em contrapartida, nota-se que há relação positiva entre a variável que mensura o total de filhos moradores do domicílio (variável num_filhos) e a probabilidade da família estar abaixo da linha de pobreza extrema. As dummies para a etnia do chefe de família (variáveis branco, negro, amarelo, pardo e indigena) não se mostraram relevantes para explicar a probabilidade de o domicílio estar abaixo da linha de pobreza extrema.

${ }^{21}$ As variáveis que medem a escolaridade média das pessoas ocupadas na família, a alfabetização e a idade do seu chefe apresentaram efeito negativo, estatisticamente significante, na probabilidade de os domicílios estarem abaixo da linha de pobreza. Novamente a variável que mensura o total de filhos moradores do domicílio apresentou relacionamento positivo com a probabilidade de pobreza e as dummies para a etnia do chefe de família não se mostraram relevantes para explicar a probabilidade de o domicílio estar abaixo da linha de pobreza. Os efeitos estimados evidenciam a similaridade entre os resultados apresentados nas Tabelas 18 e 19.
} 
Tabela 19: Efeitos Marginais das variáveis de controle na média amostral - Linha de pobreza

\begin{tabular}{|c|c|c|c|}
\hline \multicolumn{4}{|c|}{ Regressão Logística } \\
\hline \multicolumn{4}{|c|}{$\begin{array}{l}\text { Variável Dependente: } \mathrm{P}(\text { abaixo de LP1 }) \\
\text { Estatística Wald chi2 }=103.267,56-\mathrm{p} \text {-valor }=0 \\
\text { Pseudo } \mathrm{R}^{2}=0.3765\end{array}$} \\
\hline Variável & Efeito Marginal & Variável & Efeito Marginal \\
\hline idade & $-0,00809^{*}$ & renda_sm & $-0,05182^{*}$ \\
\hline casado & $0,02610^{*}$ & renda_sm96 & $0,09844^{*}$ \\
\hline num_filhos & $0,09124^{*}$ & renda_sm97 & $0,03712^{*}$ \\
\hline num_parentes & 0,00363 & renda_sm98 & $0,08490^{*}$ \\
\hline num_empregados & $-0,13870^{*}$ & renda_sm99 & $0,08377^{*}$ \\
\hline branco & $-0,02888$ & renda_sm01 & $0,04416^{*}$ \\
\hline negro & 0,02733 & renda_sm02 & $-0,00897$ \\
\hline amarelo & $-0,03614$ & renda_sm03 & $0,03890^{*}$ \\
\hline pardo & 0,01208 & renda_sm04 & $0,03871^{*}$ \\
\hline indigena & 0,03150 & renda_sm05 & $-0,02109^{*}$ \\
\hline le_e_escreve & $-0,01001^{*}$ & renda_sm06 & $-0,02565^{*}$ \\
\hline trabalho_semana & $-0,09960^{*}$ & renda_apos_sm & $-0,12895^{*}$ \\
\hline auxilio_moradia & $-0,05559^{*}$ & renda_apos_sm96 & $0,19256^{*}$ \\
\hline auxilio_alim & $-0,05830^{*}$ & renda_apos_sm97 & $0,21623^{*}$ \\
\hline auxilio_trans & $-0,06395^{*}$ & renda_apos_sm98 & $0,13784^{*}$ \\
\hline auxilio_educ & $-0,05337^{*}$ & renda_apos_sm99 & $0,12993^{*}$ \\
\hline auxilio_saud & $-0,09164^{\star}$ & renda_apos_sm01 & $0,08419^{*}$ \\
\hline escol_media & $-0,03618^{*}$ & renda_apos_sm02 & $0,09821^{*}$ \\
\hline EMPR & $-0,16024^{*}$ & renda_apos_sm03 & $0,04888^{*}$ \\
\hline CONT & $-0,09009^{*}$ & renda_apos_sm04 & $0,03949^{*}$ \\
\hline SREM & $0,05296^{*}$ & renda_apos_sm05 & $0,03177^{*}$ \\
\hline CCAR & $-0,07249^{*}$ & renda_apos_sm06 & 0,00529 \\
\hline SCAR & $-0,04846^{*}$ & renda_pens_sm & $-0,11910^{*}$ \\
\hline FPUB & $-0,10110^{*}$ & renda_pens_sm96 & $0,10253^{*}$ \\
\hline MILI & $-0,14275^{*}$ & renda_pens_sm97 & $0,12514^{*}$ \\
\hline 1996 & $-0,03861^{*}$ & renda_pens_sm98 & $0,10573^{*}$ \\
\hline 1997 & $-0,01755^{*}$ & renda_pens_sm99 & $0,11399^{*}$ \\
\hline 1998 & $-0,03272^{*}$ & renda_pens_sm01 & $0,05601^{*}$ \\
\hline 1999 & $-0,00432$ & renda_pens_sm02 & $0,07931^{*}$ \\
\hline 2001 & $0,01986^{*}$ & renda_pens_sm03 & $0,05664^{*}$ \\
\hline 2002 & $0,16293^{*}$ & renda_pens_sm04 & $0,03804^{*}$ \\
\hline 2003 & $0,05157^{*}$ & renda_pens_sm05 & 0,02556 \\
\hline 2004 & $0,04044^{*}$ & renda_pens_sm06 & $-0,00508$ \\
\hline 2005 & $0,05803^{*}$ & Num_moradores & $-0,00517$ \\
\hline 2006 & $0,01964^{*}$ & & \\
\hline
\end{tabular}

* significativo a $1 \%$. Fonte: cálculos dos autores. 
as famílias com rendimentos (do trabalho, aposentadorias e pensões) indexados ao SM, principalmente após 2002. Estes resultados fornecem evidências de que neste período, a indexação ao SM retirou muitas famílias da pobreza e pobreza extrema no Brasil. Isto pode ser notado por meio dos coeficientes estimados negativos e estatisticamente significantes, que denotam a redução da pobreza quando a família possui moradores com rendimentos indexados ao $\mathrm{SM}^{22}$. Todavia, há indícios de que tais efeitos não resultam diretamente dos fortes reajustes reais do SM no período. Estes achados parecem corroborar as estatísticas descritivas apresentadas nas seções iniciais.

\section{A necessidade de um novo paradigma}

Com base nos dados apresentados, parece correto afirmar que o SM deixou progressivamente de ser uma referência que balize o combate à extrema pobreza no Brasil. Seus aumentos sucessivos reais fizeram com que a proporção de pessoas com renda abaixo do SM aumentasse, ao mesmo tempo em que a variável foi se distanciando do rendimento das pessoas efetivamente mais pobres. Nesse contexto, ganham relevo discussões acerca da eficácia das políticas governamentais, que cotejam os benefícios distributivos associados a aumentos do SM com outras políticas governamentais melhor focalizadas, notadamente o Programa Bolsa Família (Soares 2006a).

O dado fundamental a ressaltar é que a prioridade da política social deveria ser agir sobre a insuficiência de renda das pessoas cujos rendimentos encontram-se abaixo da linha de extrema pobreza. Quando o SM aumenta, o senso comum considera que ele se aproxima do limite mínimo "efetivo" de subsistência. No entanto o efeito real é oposto: o SM distancia-se desse limite, visto estar situado acima (e não abaixo) da linha de extrema pobreza. Com isso, é relativamente reduzido o número de famílias extremamente pobres afetadas pelo $\mathrm{SM}^{23}$. A elevação do SM acentuou características do mercado de trabalho que a rigor já estavam presentes no Brasil há mais de uma década ${ }^{24}$. Jatobá \& Chahad (1997) postulavam a manutenção do caráter nacionalmente unificado do SM como referência para a Previdência Social, porém com regionalização da variável para efeitos da sua vigência no mercado de trabalho para os trabalhadores do setor privado.

Certamente o fim do papel do SM na definição das políticas públicas encontraria resistência significativa. Entretanto, é necessário atentar para o fato de que a variável não possui a relevância no combate à extrema pobreza que lhe é usualmente atribuída. Este fato é confirmado pelos dados da Tabela 20. Observa-se que de cada 100 famílias extremamente pobres do país, apenas sete tinham algum membro da família ganhando um SM (eram 14 em 2005).

A Tabela 21 complementa a informação anterior e mostra que no Brasil, de cada 100 domicílios em que ao menos um membro recebe um SM, apenas 4 são considerados extremamente pobres. (eram 8 em 2005). Nas regiões nordeste e norte, de cada 100 domicílios em que pelo menos um membro recebe um SM, só $6 \%$ são extremamente pobres.

\footnotetext{
${ }^{22}$ Assim como no modelo anterior, o teste conjunto para a igualdade destes efeitos rejeitou fortemente [Estatística $\left.X^{2}(11)=2.700,50\right]$ a hipótese de efeitos iguais entre os anos.

${ }^{23}$ Tome-se como exemplo o que ocorreu em 2001, quando o SM teve um aumento real de $11 \%$, que seguiu ao aumento real de $5 \%$ de 2000 (ver Tabela 1). Entretanto, no acumulado do biênio $2000 / 2001$, a renda média dos $20 \%$ mais pobres caiu $3 \%$.

${ }^{24}$ Sobre a efetividade regional do salário mínimo, ver Neri et al. (2000)
} 
Tabela 20: Percentual de domicílios extremamente pobres que têm algum membro com rendimento do trabalho principal exatamente igual a um SM, em relação ao total de domicílios extremamente pobres, 2005-2007 (\%)

\begin{tabular}{lrrr}
\hline Região & 2005 & 2006 & 2007 \\
\hline Brasil & 14,2 & 8,5 & 6,7 \\
Norte & 25,6 & 19,2 & 10,6 \\
Nordeste & 12,6 & 7,6 & 6,3 \\
Centro-Oeste & 13,4 & 5,3 & 4,8 \\
Sudeste & 15,5 & 7,6 & 6,7 \\
Sul & 13,0 & 9,7 & 6,7 \\
\hline Fonte: PNADs 2005-2007. & Elaboração \\
dos autores. Obs.: Linhas de pobreza ex- \\
trema regionalizadas
\end{tabular}

Tabela 21: Percentual de domicílios extremamente pobres em relação ao total de domicílios que têm algum membro com rendimento do trabalho principal exatamente igual a um salário mínimo, 2005-2007 $(\%)$

\begin{tabular}{lrrr}
\hline Região & 2005 & 2006 & 2007 \\
\hline Brasil & 7,6 & 4,1 & 3,8 \\
Norte & 12,7 & 8,9 & 5,6 \\
Nordeste & 11,9 & 6,6 & 5,5 \\
Centro-Oeste & 3,4 & 1,2 & 1,2 \\
Sudeste & 4,6 & 1,9 & 2,4 \\
Sul & 5,0 & 3,4 & 2,8 \\
\hline Fonte: PNADs 2005-2007. Elaboração \\
dos autores. Obs.: Linhas de pobreza ex- \\
trema regionalizadas
\end{tabular}

Na Tabela 22, de cada 100 domicílios que se encontram no décimo inferior da distribuição, em apenas 11 deles havia algum membro que recebia um SM. Já nos décimos posteriores, essa incidência era maior, mas em nenhum deles chegava a $25 \%$. Na média dos $30 \%$ dos domicílios considerados mais pobres, o percentual deles que têm algum membro da família com rendimento do trabalho principal exatamente igual a um SM é de apenas $18 \%$.

A distorção da política de aumentos reais do SM é mais patente no caso dos aposentados e pensionistas. Do total de pessoas desse grupo que em 2007 tinha rendimentos iguais a um SM, só $1 \%$ estava situado no décimo inferior da distribuição de renda per capita e apenas $12 \%$ se localizavam no conjunto dos três décimos inferiores da distribuição de renda (Tabela 23). A Tabela 24 é similar à anterior e mostra um quadro parecido para os trabalhadores empregados: apenas 3\% dos indivíduos que recebiam um SM de rendimento em 2007 se situavam no primeiro décimo e apenas $26 \%$ estavam localizados nos três décimos inferiores ${ }^{25}$.

Em 1995, o SM localizava-se 3\% acima da média da remuneração do se-

\footnotetext{
${ }^{25}$ É necessário notar que podem estar ocorrendo transferências de renda inter-domiciliares, que não são captadas de maneira adequada pela PNAD.
} 
Tabela 22: Percentual de domicílios que têm algum membro com rendimento do trabalho principal exatamente igual a um SM, em relação ao total de domicílios do décimo da distribuição de renda per capita, 2005-2007 (\%)

\begin{tabular}{lrrr}
\hline Décimos da distribuição & 2005 & 2006 & 2007 \\
\hline Primeiro & 16,1 & 12,9 & 11,3 \\
Segundo & 27,0 & 25,6 & 21,2 \\
Terceiro & 26,3 & 23,5 & 22,0 \\
Quarto & 26,7 & 25,3 & 23,1 \\
Quinto & 24,6 & 20,8 & 16,4 \\
Sexto & 20,8 & 20,7 & 17,6 \\
Sétimo & 16,6 & 15,5 & 11,9 \\
Oitavo & 10,9 & 10,7 & 7,6 \\
Nono & 6,7 & 6,3 & 4,2 \\
Décimo & 3,1 & 2,5 & 1,8 \\
Média & 17,9 & 16,4 & 13,7 \\
\hline
\end{tabular}

Fonte: PNADs 2005-2007. Elaboração dos autores.

Tabela 23: Distribuição dos aposentados e pensionistas com rendimento exatamente igual a um salário mínimo, por décimo da distribuição de renda per capita - 2005-2007 (\%)

\begin{tabular}{lrrr}
\hline Décimos da distribuição & 2005 & 2006 & 2007 \\
\hline Primeiro & 1,4 & 0,9 & 1,0 \\
Segundo & 4,7 & 4,4 & 5,0 \\
Terceiro & 6,0 & 5,9 & 6,3 \\
Quarto & 11,2 & 11,0 & 11,3 \\
Quinto & 11,8 & 11,8 & 11,5 \\
Sexto & 22,9 & 18,1 & 25,6 \\
Sétimo & 15,9 & 20,5 & 13,5 \\
Oitavo & 11,6 & 11,9 & 10,8 \\
Nono & 9,9 & 10,8 & 10,4 \\
Décimo & 4,6 & 4,7 & 4,7 \\
Total & 100,0 & 100,0 & 100,0 \\
\hline
\end{tabular}

Fonte: PNADs 2005-2007. Elaboração dos autores. 
Tabela 24: Distribuição dos indivíduos que recebem exatamente um salário mínimo no trabalho principal, por décimo da distribuição de renda per capita - 2005-2007 (\%)

\begin{tabular}{lrrr}
\hline Décimos da distribuição & 2005 & 2006 & 2007 \\
\hline Primeiro & 3,4 & 2,8 & 3,2 \\
Segundo & 12,1 & 11,7 & 12,4 \\
Terceiro & 10,1 & 10,3 & 10,4 \\
Quarto & 14,9 & 14,9 & 15,8 \\
Quinto & 14,6 & 14,9 & 15,4 \\
Sexto & 16,2 & 14,9 & 16,2 \\
Sétimo & 11,9 & 13,6 & 12,4 \\
Oitavo & 8,7 & 8,9 & 7,5 \\
Nono & 5,6 & 5,6 & 4,7 \\
Décimo & 2,5 & 2,4 & 2,0 \\
Total & 100,0 & 100,0 & 100,0 \\
\hline
\end{tabular}

Fonte: PNADs 2005-2007. Elaboração dos autores.

gundo décimo da distribuição de renda e 3\% abaixo da média da remuneração do terceiro décimo da distribuição de renda. Doze anos depois, o SM era equivalente a 1,41 vezes a renda média do segundo décimo, era igual a renda média do terceiro décimo e era praticamente igual $(0,98)$ à renda média do quarto décimo. No período 1995-2007, quando a renda média da população diminuiu $5 \%$, a renda do primeiro quintil aumentou $9 \%$, a do terceiro aumentou também $9 \%$ e a renda média do segundo aumentou $38 \%$. Em comparação, o salário mínimo teve um aumento real de $66 \%$. Já o terceiro décimo da distribuição de renda nesse mesmo período teve um aumento de renda de $61 \%$ (não por acaso, muito próximo ao do SM) e o quarto, de $21 \%$. Dessa forma, pode-se concluir que, em um contexto de queda da renda média, o efeito da política do SM foi aproximar do terceiro quintil a renda média daqueles que estavam no segundo quintil, influenciada pela variação na renda de quem estava no terceiro décimo da distribuição ${ }^{26}$. O que se observa é que o SM afeta um conjunto expressivo de pessoas, com predomínio, porém, daquelas que recebem benefícios previdenciários e assistenciais (INSS e LOAS/RMV). Com efeito, o número de benefícios ou de remunerações de exatamente um SM pode ser decomposto conforme apresentado na Tabela 25 , que permite avaliar a relevância do SM para diferentes grupos no triênio 2005-2007. ${ }^{27}$

\section{Comentários finais}

No trabalho, verificou-se que os aumentos reais do salário mínimo têm tido eficiência declinante no combate à extrema pobreza. No período 1994-2007, o SM teve uma variação real acumulada de quase $110 \%$. Como resultado, esta variável passou de $23 \%$ para $40 \%$ do rendimento médio no período 1995-2007.

\footnotetext{
${ }^{26}$ Em 1995, a renda do segundo quintil era de 59\% da renda do terceiro. Em 2007, essa proporção havia aumentado para $74 \%$.

${ }^{27}$ Deve ser feita a ressalva que os dados não se referem ao número de indivíduos e sim ao de benefícios emitidos. Estes números não são iguais devido à possibilidade de acumulação de alguns benefícios. Por exemplo, se uma viúva é simultaneamente pensionista e aposentada, esta pessoa será contada duas vezes como beneficiária.
} 
Tabela 25: Distribuição dos indivíduos que recebem exatamente um salário mínimo no trabalho principal, por décimo da distribuição de renda per capita - 2005-2007 (\%)

\begin{tabular}{lrrr}
\hline Categoria & \multicolumn{1}{c}{2005} & \multicolumn{1}{c}{2006} & \multicolumn{1}{c}{2007} \\
\hline Benefícios INSS & 15.217 .814 & 15.937 .722 & 16.525 .167 \\
Benefícios previdenciários & 12.425 .176 & 12.997 .011 & 13.428 .601 \\
LOAS + RMV & 2.792 .638 & 2.940 .711 & 3.096 .566 \\
Servidores públicos (inclusive militares) & 544.353 & 583.781 & 557.058 \\
Federais & 25.594 & 26.300 & 16.064 \\
Estaduais & 96.771 & 83.822 & 74.102 \\
Municipais & 421.988 & 473.659 & 466.892 \\
Setor privado & 8.071 .121 & 8.091 .909 & 7.002 .030 \\
Com carteira & 4.187 .683 & 4.719 .166 & 4.243 .835 \\
Outros & 3.883 .438 & 3.372 .743 & 2.758 .195 \\
Total (servidores públicos + setor privado) & 8.615 .474 & 8.675 .690 & 7.559 .088 \\
Total & 23.833 .288 & 24.613 .412 & 24.084 .255 \\
\hline /a Inclui auxílios. Fontes: Para os dados do INSS, AEPS (2007). Para os demais \\
dados, PNADs 2005-2007, com tabulações dos autores. & \multicolumn{3}{c}{}
\end{tabular}

Eventuais mudanças referentes à definição do SM ocorrerão em um contexto distinto daquele verificado no passado. É diferente discutir acerca da possibilidade de estabilização do SM em termos reais quando seu valor era inferior a US\$ 60, como no final de 2002 e fazê-lo quando seu valor é superior a US\$ 260 , como no momento em que esse texto está sendo finalizado. Houve crescimento significativo no poder de compra do SM, qualquer que seja a unidade de medida empregada. O aumento real do SM representou uma das principais fontes de pressão sobre as contas da Previdência Social desde o Plano Real. De 1995 a 2009 a despesa do INSS cresceu de 4,6\% para 7,3\% do PIB. Cabe ainda lembrar que em 1995 não existiam as despesas referentes aos benefícios tipo LOAS, que atualmente representam cerca de $0,6 \%$ do PIB. O dispêndio com benefícios assistenciais e previdenciários teve um aumento equivalente a 3,3\% do PIB, o que representa um incremento relativo de mais de $70 \%$ do seu peso no PIB em um período de 14 anos. Este fenômeno ocorreu em parte devido ao fato de o SM afetar 2 de cada 3 benefícios, dada a vinculação constitucional existente entre a variável e o piso previdenciário e assistencial.

Os resultados do procedimento econométrico efetuado, reportados nas Tabelas 18 e 19 permitem inferir que há algum efeito médio, de sinal positivo, resultante da indexação de benefícios previdenciários e de rendimentos do trabalho ao SM. No entanto, emergem duas evidências a partir de tais resultados. A primeira é que os efeitos têm se reduzido ao longo do tempo. Este fato pode ser notado para os coeficientes das variáveis renda_sm; renda_apos_sm e renda_pens_sm, que se reduzem de forma quase monotônica, chegando até a se tornarem negativos para o ano 2006. Esse fato é particularmente mais relevante para os efeitos do SM sobre a pobreza extrema. A segunda evidência é não parece haver relação direta entre a magnitude do aumento real do SM e o efeito marginal estimado sobre a pobreza extrema. Estas duas evidências corroboram as evidências descritivas e os pontos assinalados no início deste trabalho.

Com base nos dados apresentados e partindo-se do pressuposto de que a prioridade maior das políticas sociais deveria ser tentar reduzir a insuficiência de renda das famílias mais pobres, propõem-se aqui, para reflexão com vistas à sua adoção em algum momento futuro, três medidas, complementares entre 
si:

i) estabilizar em algum momento o valor real do piso previdenciário, mediante Emenda Constitucional que desvincule o piso do valor do SM;

ii) retomar, em função das diferenças regionais, o conceito de salário mínimo regional, que já vigorou no país, até a década de 80;

iii) redirecionar o foco das políticas sociais.

O novo foco deve estar ligado a ações integradas que visem três objetivos. O primeiro é beneficiar um maior número de pessoas situadas abaixo da linha de extrema pobreza. O segundo é ampliar os recursos à disposição dessas pessoas. E, finalmente, o terceiro é formatar políticas públicas com "porta de saída", que consigam melhorar estruturalmente as condições de ascensão social desses indivíduos e possibilitem sua retirada do elenco de beneficiários, no horizonte de uma geração ${ }^{28}$.

Há quatro motivos para postular uma mudança de política governamental de definição do salário mínimo e do piso previdenciário:

a) O fato de não haver fundamentos teóricos que embasem tais incrementos na magnitude observada. As pessoas devem ter aposentadorias compatíveis com as contribuições efetuadas durante o período laboral. O valor da aposentadoria reflete o esforço contributivo passado. Aumentos reais nos benefícios equivalem a fazer uma transferência dos recursos das gerações que estão no mercado de trabalho, fato incompatível com a noção de justiça atuarial e com o equilíbrio nas contas da previdência;

b) A inconsistência lógica da conjugação de taxas esperadas de crescimento de longo prazo do PIB e do número de idosos (ambas ao redor de $4 \%$ a.a.) com a elevação do valor real de dois terços dos benefícios, como tem ocorrido ao longo dos últimos 14 anos. Se isso ocorrer, a despesa do INSS continuará aumentando como proporção do PIB, levando provavelmente a novos e indesejados aumentos da carga tributária;

c) A percepção de que não ter ganhos futuros é completamente diferente de haver perdas em relação ao atual padrão de rendimentos. As conquistas acumuladas nos últimos 15 anos, somadas aos ganhos adicionais a serem obtidos até 2011, são bastante expressivas e serão o patamar básico daqui por diante.

d) A constatação de que o aumento do SM não é mais uma política eficiente de combate à pobreza extrema. Isso deveria ser um fator de convencimento poderoso no sentido de persuadir a sociedade acerca da razoabilidade da medida proposta.

Se o país quer atacar de forma eficiente o problema da extrema pobreza, a elevação do piso previdenciário e do SM não se configura como o instrumento mais eficaz. O seu aumento implica onerar pesadamente as contas do INSS e do Tesouro (e, portanto, de outros grupos da sociedade) com efeitos sociais

\footnotetext{
${ }^{28}$ A expressão "porta de saída" tem sido rejeitada pelo Ministério do Desenvolvimento Social e Combate à Fome, com base no argumento que revelaria certo preconceito. O ministro da pasta tem preferido usar a expressão "emancipação". Entretanto, na prática, a ideia é a mesma.
} 
modestos. Nesse sentido, programas focalizados, como o Bolsa Família, têm se revelado mais eficazes para atingir o objetivo de combater a pobreza extrema, objetivo básico das políticas sociais.

\section{Agradecimentos}

Os autores agradecem as sugestões de Paulo Levy a uma versão preliminar do artigo, assumindo, como de praxe, plena responsabilidade pelo conteúdo final do texto. Os autores são muito gratos a Marcelo Neri, pelos comentários feitos quando da apresentação de uma versão preliminar deste texto, no XXXVII Encontro da Anpec, em 2009.

\section{Referências Bibliográficas}

Barros, R. P. d. (2007), A efetividade do salário mínimo em comparação à do programa bolsa família como instrumento de redução da pobreza e da desigualdade, in 'Desigualdade de renda no Brasil: uma análise da queda recente', Brasília: IPEA.

Barros, R. P. d. \& Carvalho, M. (2005), 'Salário mínimo e distribuição de renda', Seminários DIMAC, No 196.

Barros, R. P. d., Carvalho, M. \& Franco, S. (2004), 'Distribuição de renda, pobreza e desigualdade no brasil', Ipea/IBGE/CEPAL.

Barros, R. P. d., Carvalho, M., Franco, S. \& Mendonça, R. (2006), 'Conseqüências e causas imediatas da queda recente da desigualdade de renda brasileira', IPEA.

Barros, R. P. d., Corseuil, C. H. \& Cury, S. (2000), 'Salário mínimo e pobreza no brasil: uma abordagem de equilíbrio geral', Pesquisa e Planejamento Econômico 30, 157-182.

Ferreira, F. H. G., Leite, P. G. \& Litchfield, J. A. (2006), 'The rise and fall of brazilian inequality: 1981-2004', World Bank Policy Research Working Paper.

Firpo, S. \& Reis, M. C. (2006), 'Minimum wage effects on labor earnings inequality: some evidence from brazil', Trabalho apresentado no XXVIII Encontro Brasileiro de Econometria. Salvador.

Firpo, S. \& Reis, M. C. (2007), O salário mínimo e a queda recente da desigualdade no brasil, in 'Desigualdade de renda no Brasil: uma análise da queda recente. Vol. 2. Brasília', IPEA.

Foster, J., GREER, J. \& THORBECKE (1984), 'A class of decomposable poverty measure', Econometrica 52.

Greene, W. H. (2003), Econometric Analysis, Prentice-hall.

Groedhart, T., Halberstadt, V., Kapteyn, A. \& Van Praag, B. (1977), 'The poverty line: concept and measurement', Journal of Human Resources 12, 503520 .

Hagenaars, A. \& Van Praag, B. (1985), 'A synthesis of poverty line definitions', Review of Income and Wealth 31, 139-154. 
Hoffman, R. (1998), Distribuição de renda: medidas de desigualdade e pobreza, São Paulo: Editora da Universidade de São Paulo.

Jatobá, J. \& Chahad, J. P. (1997), O papel do salário mínimo no contexto da estabilidade econômica, IPEA.

Neri, M., Gonzaga, G. \& Camargo (2000), Distribuição regional da efetividade do salário mínimo no Brasil, EPGE.

Neri, M., Gonzaga, G. \& Camargo, J. M. (2001), 'Salário mínimo, 'efeito farol' e pobreza', Revista de Economia Política 21.

Neri, M., Kakwani, N. \& Son, H. (2006), 'Ingredientes trabalhistas e culinária da estagnação', Conjuntura Econômica.

Ramos, L. \& Reis (1995), 'Salário mínimo, distribuição de renda e pobreza no brasil', Pesquisa e Planejamento Econômico 25.

Ramos, L. \& Reis, J. G. (1993), Quem ganha um salário mínimo no Brasil?, IPEA.

Ravallion, M., Chen, S. \& Sangraula, P. (2008), 'Dollar a day revisited', Policy Research Working Paper 4620.

Saboia, J. (2006), 'Salário mínimo e combate à pobreza', Valor Econômico .

Saboia, J. (2007a), O salário mínimo e seu potencial para a melhoria da distribuição de renda no brasil, in 'Desigualdade de renda no Brasil: uma análise da queda recente', IPEA.

Saboia, J. (2007b), 'É hora de mudar a previdência', O Globo .

Soares, S. (2006a), 'Distribuição de renda no brasil de 1976 a 2004 com ênfase no período entre 2001 e 2004', IPEA. Texto para Discussão.

Soares, S. (2006b), A educação no Brasil rural, Technical report, INEP.

Souza, P. R. C. \& Baltar, P. E. d. A. (1982), The minimum wage and wage rates in brazil, Technical report, Brazilian Economic Studies.

Velloso, R. C. (1990), 'Salário mínimo e taxa de salários: o caso brasileiro', Pesquisa e Planejamento Econômico 20.

Wooldridge, J. M. (2002), Econometric Analysis of Cross Section and Panel Data, MIT Press.

\section{Apêndice A Estatísticas descritivas}


Tabela A.1: Estatísticas descritivas

\begin{tabular}{|c|c|c|c|c|c|}
\hline Variável & Descrição & Média & Desvio-Padrão & Min. & Max. \\
\hline P_abaixoLP & $\begin{array}{l}\text { Prob. de renda domic. per } \\
\text { capita abaixo da linha de } \\
\text { pobreza regional }\end{array}$ & 0,28673 & 0,45223 & 0 & 1 \\
\hline P_abaixoLP1 & $\begin{array}{l}\text { Prob. de renda domic. per } \\
\text { capita abaixo da linha de } \\
\text { pobreza extrema regional }\end{array}$ & 0,11210 & 0,31500 & 0 & 1 \\
\hline idade & $\begin{array}{l}\text { Idade em anos do chefe da } \\
\text { família }\end{array}$ & 46,14686 & 15,45275 & 10 & 110 \\
\hline casado & $\begin{array}{l}\text { Dummy para estado civil do } \\
\text { chefe da família }\end{array}$ & 0,68499 & 0,46452 & 0 & 1 \\
\hline num_filhos & $\begin{array}{l}\text { Número de filhos moradores } \\
\text { do domicílio }\end{array}$ & 1,54165 & 1,41934 & 0 & 14 \\
\hline num_parentes & $\begin{array}{l}\text { Número de parentes } \\
\text { moradores do domicílio }\end{array}$ & 0,35463 & 0,88024 & 0 & 18 \\
\hline num_empregados & $\begin{array}{l}\text { Número de empregados } \\
\text { moradores do domicílio }\end{array}$ & 0,00566 & 0,08628 & 0 & 4 \\
\hline branco & $\begin{array}{l}\text { Dummy para etnia branca do } \\
\text { chefe da família }\end{array}$ & 0,51013 & 0,49990 & 0 & 1 \\
\hline negro & $\begin{array}{l}\text { Dummy para etnia negra do } \\
\text { chefe da família }\end{array}$ & 0,07554 & 0,26427 & 0 & 1 \\
\hline amarelo & $\begin{array}{l}\text { Dummy para etnia amarela } \\
\text { do chefe da família }\end{array}$ & 0,00438 & 0,06606 & 0 & 1 \\
\hline pardo & $\begin{array}{l}\text { Dummy para etnia parda do } \\
\text { chefe da família }\end{array}$ & 0,40731 & 0,49133 & 0 & 1 \\
\hline indigena & $\begin{array}{l}\text { Dummy para etnia indígena } \\
\text { do chefe da família }\end{array}$ & 0,00255 & 0,05047 & 0 & 1 \\
\hline le_e_escreve & $\begin{array}{l}\text { Dummy para alfabetização } \\
\text { do chefe da família }\end{array}$ & 0,84135 & 0,36535 & 0 & 1 \\
\hline trabalho_semana & $\begin{array}{l}\text { Dummy para trabalho na } \\
\text { semana de referência do } \\
\text { chefe da família }\end{array}$ & 0,71912 & 0,44943 & 0 & 1 \\
\hline auxilio_moradia & $\begin{array}{l}\text { Dummy para recebimento de } \\
\text { auxílio moradia }\end{array}$ & 0,05568 & 0,22931 & 0 & 1 \\
\hline auxilio_alim & $\begin{array}{l}\text { Dummy para recebimento de } \\
\text { auxílio alimentação }\end{array}$ & 0,32176 & 0,46715 & 0 & 1 \\
\hline auxilio_trans & $\begin{array}{l}\text { Dummy para recebimento de } \\
\text { auxílio transporte }\end{array}$ & 0,29680 & 0,45685 & 0 & 1 \\
\hline auxilio_edu & $\begin{array}{l}\text { Dummy para recebimento de } \\
\text { auxílio educação }\end{array}$ & 0,02415 & 0,15353 & 0 & 1 \\
\hline auxilio_saud & $\begin{array}{l}\text { Dummy para recebimento de } \\
\text { auxílio saúde }\end{array}$ & 0,14862 & 0,35571 & 0 & 1 \\
\hline escolaridade & $\begin{array}{l}\text { Escolaridade em anos do } \\
\text { chefe da família }\end{array}$ & 6,65955 & 4,59236 & 1 & 17 \\
\hline EMPR & $\begin{array}{l}\text { Dummy para chefe da } \\
\text { família empregador }\end{array}$ & 0,03869 & 0,19286 & 0 & 1 \\
\hline CONT & $\begin{array}{l}\text { Dummy para chefe da } \\
\text { família trabalhador conta } \\
\text { própria }\end{array}$ & 0,16161 & 0,36810 & 0 & 1 \\
\hline SREM & $\begin{array}{l}\text { Dummy para chefe da } \\
\text { família empregado não } \\
\text { remunerado }\end{array}$ & 0,00394 & 0,06264 & 0 & 1 \\
\hline
\end{tabular}

Fonte: cálculos dos autores 
Tabela A.1: Estatísticas descritivas (continuação)

\begin{tabular}{|c|c|c|c|c|c|}
\hline Variável & Descrição & Média & Desvio-Padrão & Min. & Max. \\
\hline CCAR & $\begin{array}{l}\text { Dummy para chefe da } \\
\text { família empregado com } \\
\text { carteira assinada }\end{array}$ & 0,20504 & 0,40373 & 0 & 1 \\
\hline SCAR & $\begin{array}{l}\text { Dummy para chefe da } \\
\text { família empregado sem } \\
\text { carteira assinada }\end{array}$ & 0,07187 & 0,25827 & 0 & 1 \\
\hline FPUB & $\begin{array}{l}\text { Dummy para chefe da } \\
\text { família funcionário público } \\
\text { estatutário }\end{array}$ & 0,05363 & 0,22529 & 0 & 1 \\
\hline MILI & $\begin{array}{l}\text { Dummy para chefe da } \\
\text { família militar }\end{array}$ & 0,00310 & 0,05559 & 0 & 1 \\
\hline renda_sm & $\begin{array}{l}\text { Dummy para rend. do } \\
\text { trabalho indexado pelo } \\
\text { salário mínimo (até } 6 \mathrm{SM} \text { ). }\end{array}$ & 0,34917 & 0,47671 & 0 & 1 \\
\hline renda_apos_sm & $\begin{array}{l}\text { Dummy para rend. de } \\
\text { aposent. indexado pelo } \\
\text { salário mínimo (até } 6 \mathrm{SM} \text { ). }\end{array}$ & 0,14484 & 0,35194 & 0 & 1 \\
\hline renda_pens_sm & $\begin{array}{l}\text { Dummy para rend. de } \\
\text { pensão indexado pelo salário } \\
\text { mínimo (até } 6 \mathrm{SM} \text { ). }\end{array}$ & 0,07184 & 0,25823 & 0 & 1 \\
\hline UF1 até UF27 & Dummies para UFs & & & & \\
\hline ANO1 até ANO11 & $\begin{array}{l}\text { Dummies para anos } 1996 \text { até } \\
2007\end{array}$ & & & & \\
\hline recebe_PBF & $\begin{array}{l}\text { Dummy para recebimento de } \\
\text { Bolsa Família a partir de } \\
2003\end{array}$ & 0,05124 & 0,22049 & 0 & 1 \\
\hline recebe_PBE & $\begin{array}{l}\text { Dummy para recebimento de } \\
\text { Bolsa Escola em } 2001 \text { e } 2002\end{array}$ & 0,00711 & 0,08405 & 0 & 1 \\
\hline renda_sm96 & $\begin{array}{l}\text { Dummy de interação: } \\
\text { renda_sm * dummy ano } 1996\end{array}$ & 0,02007 & 0,14025 & 0 & 1 \\
\hline renda_sm97 & $\begin{array}{l}\text { Dummy de interação: } \\
\text { renda_sm * dummy ano } 1997\end{array}$ & 0,03010 & 0,17087 & 0 & 1 \\
\hline renda_sm98 & $\begin{array}{l}\text { Dummy de interação: } \\
\text { renda_sm * dummy ano } 1998\end{array}$ & 0,02531 & 0,15706 & 0 & 1 \\
\hline renda_sm99 & $\begin{array}{l}\text { Dummy de interação: } \\
\text { renda_sm * dummy ano } 1999\end{array}$ & 0,02092 & 0,14310 & 0 & 1 \\
\hline renda_sm01 & $\begin{array}{l}\text { Dummy de interação: } \\
\text { renda_sm * dummy ano } 2001\end{array}$ & 0,02693 & 0,16187 & 0 & 1 \\
\hline renda_sm02 & $\begin{array}{l}\text { Dummy de interação: } \\
\text { renda_sm *dummy ano } 2002\end{array}$ & 0,04624 & 0,21000 & 0 & 1 \\
\hline renda_sm03 & $\begin{array}{l}\text { Dummy de interação: } \\
\text { renda_sm * dummy ano } 2003\end{array}$ & 0,03187 & 0,17566 & 0 & 1 \\
\hline renda_sm04 & $\begin{array}{l}\text { Dummy de interação: } \\
\text { renda_sm * dummy ano } 2004\end{array}$ & 0,02937 & 0,16884 & 0 & 1 \\
\hline renda_sm05 & $\begin{array}{l}\text { Dummy de interação: } \\
\text { renda_sm * dummy ano } 2005\end{array}$ & 0,04801 & 0,21379 & 0 & 1 \\
\hline renda_sm06 & $\begin{array}{l}\text { Dummy de interação: } \\
\text { renda_sm * dummy ano } 2006\end{array}$ & 0,03876 & 0,19301 & 0 & 1 \\
\hline renda_sm07 & $\begin{array}{l}\text { Dummy de interação: } \\
\text { renda_sm * dummy ano } 2007\end{array}$ & 0,03160 & 0,17492 & 0 & 1 \\
\hline
\end{tabular}

Fonte: cálculos dos autores 
Tabela A.1: Estatísticas descritivas (continuação)

\begin{tabular}{|c|c|c|c|c|c|}
\hline Variável & Descrição & Média & Desvio-Padrão & Min. & Max. \\
\hline renda_apos_96 & $\begin{array}{l}\text { Dummy de interação: } \\
\text { renda_apos *dummy ano } \\
1996\end{array}$ & 0,00893 & 0,09410 & 0 & 1 \\
\hline renda_apos_97 & $\begin{array}{l}\text { Dummy de interação: } \\
\text { renda_apos * dummy ano } \\
1997\end{array}$ & 0,01150 & 0,10660 & 0 & 1 \\
\hline renda_apos_98 & $\begin{array}{l}\text { Dummy de interação: } \\
\text { renda_apos * dummy ano } \\
1998\end{array}$ & 0,01191 & 0,10848 & 0 & 1 \\
\hline renda_apos_99 & $\begin{array}{l}\text { Dummy de interação: } \\
\text { renda_apos * dummy ano } \\
1999\end{array}$ & 0,01166 & 0,10736 & 0 & 1 \\
\hline renda_apos_01 & $\begin{array}{l}\text { Dummy de interação: } \\
\text { renda_apos *dummy ano } \\
2001\end{array}$ & 0,01231 & 0,11026 & 0 & 1 \\
\hline renda_apos_02 & $\begin{array}{l}\text { Dummy de interação: } \\
\text { renda_apos * dummy ano } \\
2002\end{array}$ & 0,01508 & 0,12186 & 0 & 1 \\
\hline renda_apos_03 & $\begin{array}{l}\text { Dummy de interação: } \\
\text { renda_apos *dummy ano } \\
2003\end{array}$ & 0,01473 & 0,12048 & 0 & 1 \\
\hline renda_apos_04 & $\begin{array}{l}\text { Dummy de interação: } \\
\text { renda_apos * dummy ano } \\
2004\end{array}$ & 0,01380 & 0,11668 & 0 & 1 \\
\hline renda_apos_05 & $\begin{array}{l}\text { Dummy de interação: renda } \\
\text { apos * dummy ano } 2005\end{array}$ & 0,01586 & 0,12492 & 0 & 1 \\
\hline renda_apos_06 & $\begin{array}{l}\text { Dummy de interação: renda } \\
\text { apos * dummy ano } 2006\end{array}$ & 0,01496 & 0,12140 & 0 & 1 \\
\hline renda_apos_07 & $\begin{array}{l}\text { Dummy de interação: renda_ } \\
\text { apos * dummy ano } 2007\end{array}$ & 0,01410 & 0,11790 & 0 & 1 \\
\hline renda_pension_96 & $\begin{array}{l}\text { Dummy de interação: } \\
\text { renda_pens * dummy ano } \\
1996\end{array}$ & 0,00467 & 0,06816 & 0 & 1 \\
\hline renda_pension_97 & $\begin{array}{l}\text { Dummy de interação: } \\
\text { renda_pens * dummy ano } \\
1997\end{array}$ & 0,00522 & 0,07204 & 0 & 1 \\
\hline renda_pension_98 & $\begin{array}{l}\text { Dummy de interação: } \\
\text { renda_pens * dummy ano } \\
1998\end{array}$ & 0,00566 & 0,07500 & 0 & 1 \\
\hline renda_pension_99 & $\begin{array}{l}\text { Dummy de interação: } \\
\text { renda_pens * dummy ano } \\
1999\end{array}$ & 0,00519 & 0,07184 & 0 & 1 \\
\hline renda_pension_01 & $\begin{array}{l}\text { Dummy de interação: } \\
\text { renda_pens * dummy ano } \\
2001\end{array}$ & 0,00594 & 0,07682 & 0 & 1 \\
\hline renda_pension_02 & $\begin{array}{l}\text { Dummy de interação: } \\
\text { renda_pens * dummy ano } \\
2002\end{array}$ & 0,00751 & 0,08631 & 0 & 1 \\
\hline renda_pension_03 & $\begin{array}{l}\text { Dummy de interação: } \\
\text { renda_pens * dummy ano } \\
2003\end{array}$ & 0,00685 & 0,08248 & 0 & 1 \\
\hline
\end{tabular}

Fonte: cálculos dos autores 
Tabela A.1: Estatísticas descritivas (continuação)

\begin{tabular}{|c|c|c|c|c|c|}
\hline Variável & Descrição & Média & Desvio-Padrão & Min. & Max. \\
\hline renda_pension_04 & $\begin{array}{l}\text { Dummy de interação: } \\
\text { renda_pens * dummy ano } \\
2004\end{array}$ & 0,00677 & 0,08200 & 0 & 1 \\
\hline renda_pension_05 & $\begin{array}{l}\text { Dummy de interação: } \\
\text { renda_pens * dummy ano } \\
2005\end{array}$ & 0,00850 & 0,09182 & 0 & 1 \\
\hline renda_pension_06 & $\begin{array}{l}\text { Dummy de interação: } \\
\text { renda_pens * dummy ano } \\
2006\end{array}$ & 0,00784 & 0,08818 & 0 & 1 \\
\hline renda_pension_07 & $\begin{array}{l}\text { Dummy de interação: } \\
\text { renda_pens * dummy ano } \\
2007\end{array}$ & 0,00771 & 0,08748 & 0 & 1 \\
\hline UF1-27 & Dummies dos estados 1 a 27 & 0 & 1 & & \\
\hline ANO1 a 11 & Dummies dos anos 1 a 27 & 0 & 1 & & \\
\hline escol_media & $\begin{array}{l}\text { Escolaridade média do chefe } \\
\text { da família }\end{array}$ & 7,59860 & 3,97834 & 1 & 17 \\
\hline renda_sm & Renda (em SM) & 0,34917 & 0,47671 & 0 & 1 \\
\hline renda_apos_sm & $\begin{array}{l}\text { Valor da aposentadoria (em } \\
\text { SM) }\end{array}$ & 0,14484 & 0,35194 & 0 & 1 \\
\hline renda_pension_m & Valor da pensão (em SM) & 0,07184 & 0,25823 & 0 & 1 \\
\hline
\end{tabular}

Fonte: cálculos dos autores 